\title{
Thrust Production Mechanisms in Hollow Cathode Microthrusters
}

\author{
A. N. Grubisic and S. B. Gabriel \\ University of Southampton \\ Highfield, Southampton, SO17 1ST, United Kingdom \\ +44 (0) 7827963838 \\ A.Grubisic@soton.ac.uk
}

\begin{abstract}
Hollow cathode have recently been investigated at the University of Southampton as potential standalone microthrusters. ${ }^{12}$ Thrust measurements suggest that in some cases, hollow cathodes are able to generate specific impulse of over 1000s with xenon. The means by which hollow cathodes are able to generate such high levels of specific impulse is not clearly understood. This paper explores thrust production mechanisms in the T5, T6 and XIPS hollow cathodes based on thrust performance and ion energy measurements. Analysis suggests the total thrust produced includes components of gas dynamic thrust particularly as a result of an intense electron pressure at the cathode exit, but also shows evidence for magneto-hydro-dynamic (MHD) forces at high currents and low flow rates arising from the self-induced azimuthal magnetic field within the orifice and resulting cross-field interaction plasma. Data may also suggest ion acceleration due to plasma potential hills. While this initial characterization can only loosely attribute the relative magnitude each mechanism plays it does show evidence for each. This research shows that with further development based on an understanding of the thrust mechanism, hollow cathodes thrusters could present significant refinements to the technology of electric propulsion.
\end{abstract}

\section{TABLE OF CONTENTS}

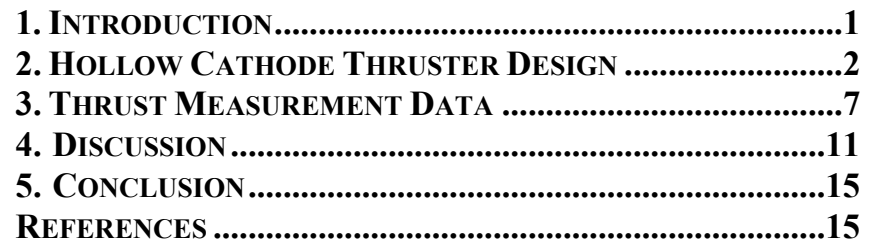

\section{NOMENCLATURE}

$\begin{array}{lll}\alpha & = & \text { Degree of ionization } \\ \mathrm{A} & = & \text { Area, } \mathrm{m}^{2} \\ \mathrm{Cp} & = & \text { Specific heat capacity, } \mathrm{J} / \mathrm{kg} \cdot \mathrm{K} \\ \mathrm{C} & = & \text { Thermal conductivity } \\ \gamma & = & \text { Ratio of specific heats } \\ \mathrm{d} & = & \text { Diameter, } \mathrm{m} \\ \mathrm{\varepsilon i} & = & \text { Ionization potential, } \mathrm{eV}\end{array}$

${ }^{1}$ 978-1-4244-3888-4/10/\$25.00 (C)2010 IEEE

${ }^{2}$ IEEEAC paper\#1485, Version 2, Updated 2010:01:13

$\begin{array}{ll}\varepsilon & = \\ \mathrm{e} & = \\ \mathrm{F} & = \\ \mathrm{f} & = \\ \mathrm{I} & = \\ \mathrm{J} & = \\ \mathrm{k} & = \\ \mathrm{L} & = \\ \mathrm{M} & = \\ \dot{m} & = \\ \mathrm{n} & = \\ \mathrm{P} & = \\ \mathrm{p} & = \\ \mathrm{q} & = \\ \mathrm{r} & = \\ \mathrm{T} & = \\ \mathrm{V} & = \\ & = \\ \mu & = \\ \mathrm{Vp} & \\ \mathrm{V} & = \\ \sigma & \end{array}$

\section{Subscript}

A

n

c

ci

$\mathrm{D}$

e

eq

ex

f

$\mathrm{k}$

or

$\mathrm{p}$

prop

$\mathrm{s}$

th
Emissivity

Electron charge, $\mathrm{C}$

Force, N

View factor

Current, A

Current density, $\mathrm{A} \cdot \mathrm{m}^{-2}$

Boltzman's constant

Characteristic length, $\mathrm{m}$

Particle mass, kg

Mass flow rate, $\mathrm{kg} \cdot \mathrm{s}^{-1}$

Plasma density, $\mathrm{m}^{-3}$

Power, W

Pressure, Pa

Radiative heat flux, W

Radius, $m$

Temperature, $\mathrm{K}$

Potential, V

Critical ionization current ratio

Permeability of free space

Plasma potential, $\mathrm{V}$

Velocity, $\mathrm{m} \cdot \mathrm{s}^{-1}$

Electrical conductivity, $\mathrm{Ohm} \cdot \mathrm{m}^{-1}$ 


\section{INTRODUCTION}

Within the University of Southampton there has been an ongoing research effort to develop the T5 and T6 hollow cathodes $(\mathrm{HC})$ for use as standalone microthrusters. The cathode test articles are a mature technology developed extensively over the last 35-years for application on the UK-10, UK-25, T5 and T6 gridded ion thrusters 123456 and as an electron source for various ion beam neutralization applications. ${ }^{7}$ Recent experiments on a T6 discharge cathode $a$ by Gessini $t$ the University of Southampton found that practical thrust could be generated with reasonable specific impulse (up to 500s). ${ }^{89}{ }^{10}$ Such performance strengthened interest in the use of all-electric propulsion systems composing high specific impulse primary electric propulsion augmented by a $\mathrm{HC}$ microthruster reaction control system (RCS). ${ }^{11}{ }^{12}$ For some missions such a configuration presents considerable mass savings over configurations where the attitude and orbit control system (AOCS) composes both a chemical RCS and primary electric system, primarily through the sharing of a common propellant bus and power processing subsystems but also through the potentially high specific impulse of the RCS. While secondary chemical RCS systems constitute a relatively large fraction of the overall propulsion system mass $^{13} \quad 14 \quad 15 \quad 16$ these systems also bring substantial expenditure in manufacture, assembly, integration, testing and launch preparation due to the use of hazardous propellants. ${ }^{17}$ General attempts to scale down electrostatic and electromagnetic thrusters for such a role have however yielded relatively poor performance, ${ }^{18}$ primarily due to high wall losses from the higher surface area to volume ratios and call for a more adequate solution. The work of Gessini ${ }^{19}$ also highlighted very low thrust efficiency, which dropped well below $1 \%$, particularly at higher values of specific impulse, leading to requirements comparable to primary propulsion systems $(>600 \mathrm{~W})$. If hollow cathodes are to have a realistic application they must be developed to show higher thrust efficiencies and at least be able to contend with resistojets in terms of their performance (15-48s with xenon $)^{20}{ }^{21}$ while operating in the $20-50 \mathrm{~W}$ power range. Figure 1 shows the general thrust to power ratios position of electric thrusters and the current position of HC thrusters based on the work of Gessini.

Since the means by which hollow cathodes are able to generate such high levels of specific impulse is not understood the method by which to improve performance of is not clear. This work therefore aims to understand the influence of terminal parameters of discharge current, mass flowrate and cathode geometry on discharge characteristics and thrust production mechanisms in hollow cathodes and in doing so develop means to improve performance. It is clear that in order to be competitive with conventional propulsion systems $\mathrm{HC}$ thrusters must be able to show thrust to power ratios $\sim 1 \mathrm{~W} / \mathrm{mN}$ and $>100$ s to be competitive with resistojets and $\sim 10 \mathrm{~W} / \mathrm{mN}$ with $>250$ s to compete with colloid thrusters and DC arcjets and demonstrate efficiencies of at least $20 \%$.

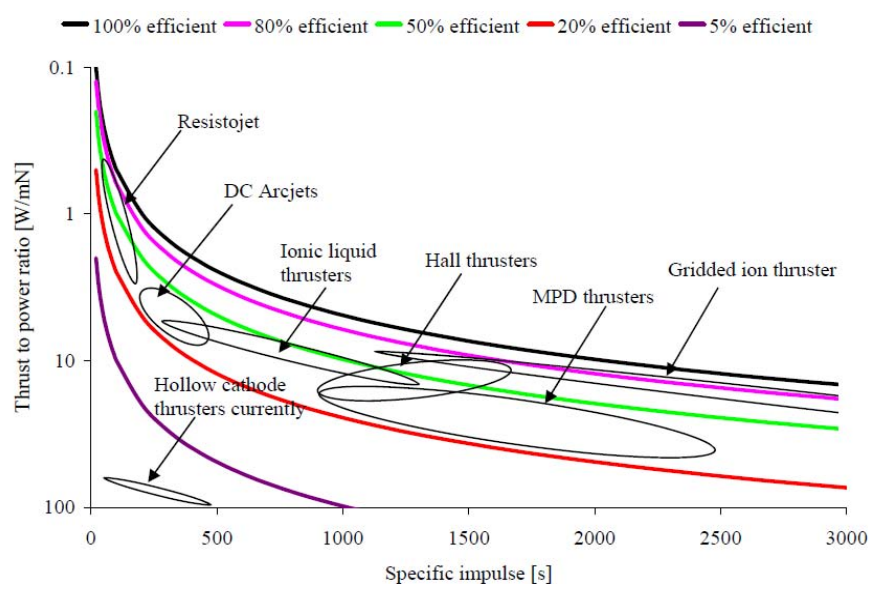

Figure 1 Thruster capability based on thrust to power ratio, specific impulse and efficiency

In order to characterize thrus performance of various cathode and indirect pendulum micro-thrust balance and supporting architecture based on a laser optical lever was consdructed. ${ }^{22}$ The T6 and later the T5 cathodes were then characterized in a number of different geometrical configurations with subsequent design iterations. ${ }^{23} 24 \quad 25$ Finally, in an attempt to understand the relationship between the existence of high energy ion populations in hollow cathode discharges and the likely thrust production mechanisms, ion energy measurements were conducted at NASA Jet Propulsion Laboratory on a $1 / 4$ inch XIPS cathode with a similar geometrical configuration to the most refined T6 cathode design. ${ }^{26}$ This paper will present a review of the thruster design philosophy and analysis of experimental results.

\section{Hollow CATHODE Thruster DESIGN}

A full and detailed review of the operation of hollow cathodes is given in ${ }^{23,24,25}$. In our case we will cover design of the anode assembly since anode design was judged as key in increasing hollow cathode thruster efficiency by controlling the spot to plume mode transition point. Understanding of the thermal flux to the anode was also necessary in to prevent overheating of the thruster assembly.

\section{A. Power Balance}

A schematic of the energy flux within a cathode is shown in Figure 2. The electron or ion temperature in volts is given by: 
$\frac{k T}{e}$

The thermal power of a convected flow is thus given by:

$$
I \frac{5 k T}{2 e}
$$

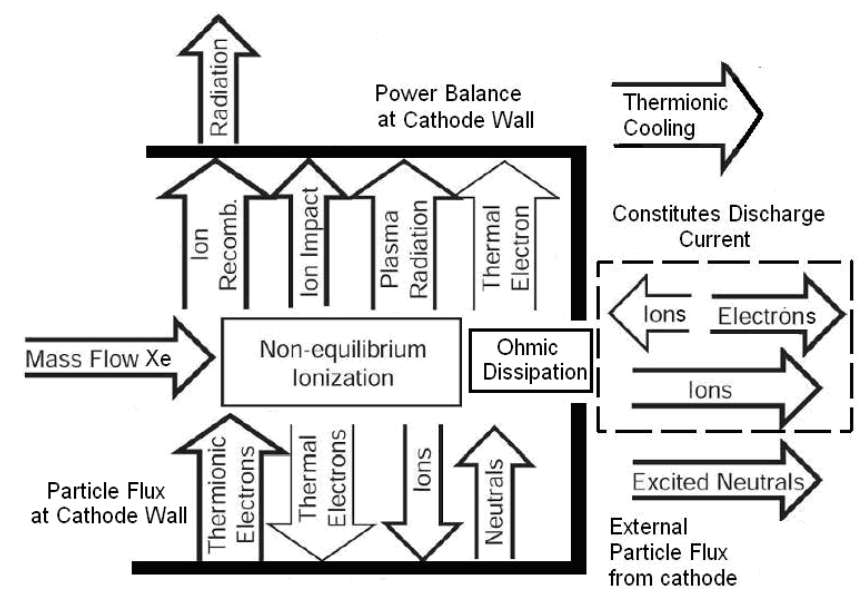

Figure 2 Energy/particle flux within a cathode

At the cathode surface the power balance is therefore represented by:

$$
\begin{gathered}
\int J_{t h}\left(\phi_{e f f}+\frac{5 k T_{c}}{2 e}\right) d A_{e m}= \\
\int J_{i}\left(\varepsilon_{i}+V_{f}-\phi_{e f f}\right) d A_{e m}+\int J_{e}\left(\phi_{e f f}+\frac{5 k T_{e}}{2 e}\right) d A_{e m}-f\left(I_{r}\right.
\end{gathered}
$$

With a view factor from the emitter to the cathode body:

$$
f=\frac{A_{e m}}{A_{s}}
$$

Integrals allow for the resulting variation in current density from the emitter. ${ }^{27}{ }^{28}$, Equivalent ion current is defined by:

$$
I_{e q}=\frac{e \dot{m}}{M_{i}}
$$

Mass flow rates between 0.05 and $1 \mathrm{mg} / \mathrm{s}$ of xenon therefore correspond to $I_{e q}$ flowrates between $0.034 \mathrm{~A}$ and $0.698 \mathrm{~A}$ respectively. Within the plasma the energy balance can be represented by:

$$
\begin{gathered}
\int J_{t h}\left(V_{p}+\frac{5 k T_{e}}{2 e}\right) d A_{e m}+\int \frac{J_{D}^{2}}{\sigma} d V= \\
\int J_{i}\left(\varepsilon_{i}+\frac{5 k T_{i}}{2 e}\right) d A_{s}+\int J_{e}\left(\frac{5 k T_{e}}{2 e}\right) d A_{s} \\
+\left(I_{D}+\alpha I_{e q}\right)\left(\frac{5 k T_{e}}{2 e}\right)+\frac{I_{e q}}{\alpha}\left(\frac{5 k T_{e}}{2 e}\right)+q_{r}
\end{gathered}
$$

\section{B. Plume Mode}

Control of plume mode is essential in maintaining low voltage operation and low noise. If the flux of ions into the cathode-anode gap is sufficient, the anode will passively collect the discharge current from the plasma; this type of operation is referred to as spot mode. If the ion flux to the cathode-keeper gap is insufficient for the anode to passively collect the electron current, an additional sheath and voltage drop forms between the plasma and anode to facilitate ionization and electron transport/collection so that electrons can traverse the gap within the quasi-neutral plasma. This transition, depicted in Figure 3, occurs as the mass flow rate or discharge current is decreased (both of which intrinsically influence plasma and discharge properties) beyond a critical point and is generally termed plume mode given that the bright spot at the cathode tip transitions into a more diffuse-like plume. Since the ions created in the gap have some fraction of the discharge potential to accelerate them toward the cathode plume mode is particularly associated with ion sputtering of the cathode orifice ${ }^{29}$ and discharge instabilities, which limit lifetime ${ }^{30}$ and are responsible for high coupling voltages. For these reasons cathodes are normally operated in spot mode.

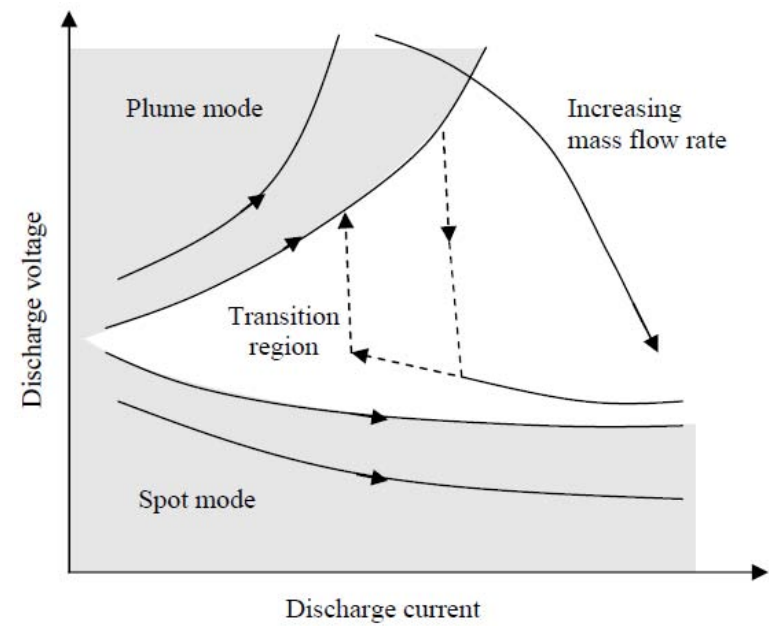

Figure 3 Hollow cathode discharge behavior with varying current and flowrate

The significant increase in discharge voltage distinctive of plume mode also significantly increases the discharge power for a fixed discharge current based on the 
relationship:

$$
P_{D}=I_{D} V_{D}
$$

Since the thrust mechanism, be it electrothermal, electromagnetic or electrostatic will be principally a function of the discharge current rather than the discharge voltage, one understandable way to increase thrust efficiency is to decrease the operating voltage. In addition the extension of spot mode like operation will inevitably enable operation at lower mass flowrates and higher specific powers $(\mathrm{J} / \mathrm{mg})$ allowing increased specific impulse.

An empirical transition to spot mode criterion $^{31}$ has been described by Kaufman, which accurately predicted the transition flow rate. Mandel and Katz ${ }^{32}$ have numerically determined this transition on the basis of the contact area of the anode and keeper electrode with the downstream plasma. Assuming a quazi-neutral plasma, the passive flux of electrons and ions to a keeper electrode immersed in the downstream plasma, based on thermal flux, is given by:

$$
I_{e, i}=A_{k} n_{e} \sqrt{\frac{e T_{e, i}}{2 \pi m_{e, i}}}
$$

In an open diode configuration all of the discharge current is drawn to the keeper. If the passive current exceeds the discharge current the keeper will be negative relative to its local plasma potential in order to achieve current balance. In this condition relatively little electron acceleration occurs in the cathode keeper gap in order to give the necessary excitation/ionization to carry the discharge current and spot mode is maintained. If the passive current is insufficient to provide the discharge current demanded from the power supply, remembering that the power supply is operating in a current limited mode, the keeper potential must be positive with respect to its local plasma potential forming an area enhancing sheath and causing electron acceleration towards the keeper with an associated glow in the cathode keeper region.

The efficiency of ionization within the cathode in spot mode is hypothesized to be sufficient to emit ions to neutralize the plasma in the cathode-to-keeper gap. Hence, the discharge fails to exhibit visual evidence of electron-impact ionization. In contrast, plume-mode emission exhibits both a luminous plume downstream of the cathode and large current and voltage oscillations typically at several megahertz.

\section{Current Collection Analytical Model}

From this understanding of hollow cathode operation we can state that in order to improve the thrust efficiency above that currently demonstrated it is likely that we can:
1. Extend the range of spot mode operation by increasing the available anode contact for electron collection from the plasma and maintaining passive discharge current collection at the anode surface. This will also:

2. Lower discharge voltage for the same demanded current thus increasing efficiency

3. Enable operation at higher specific powers giving higher specific impulse

Assuming a quazi-neutral plasma, the plasma density, $n_{i}$, can be calculated by assuming the flowrate equals the thermal efflux through the orifice cross section, i.e. assuming the drift velocity is equal to the thermal random velocity in the direction of the outlet with net flux equal to the propellant flow rate. Ion mass and temperatures are used for calculation of the plasma density since ions have much lower mobility and thus will drive the density function. At the outlet where a sudden change in plasma density is expected, this can serve as a first approximation.

$$
n_{i}=\frac{\dot{m}}{A_{0} e}\left(\frac{e T_{i}}{2 \pi m_{i}}\right)^{-1 / 2}
$$

At the anode surface the passive discharge current is given by:

$$
I_{A}=\int J_{i}+J_{e} d A
$$

Thus for a cylindrical anode:

$$
\begin{gathered}
I_{e, i}=J_{e, i} \pi d_{a} L_{a} \\
I_{A}=I_{e}+I_{i}
\end{gathered}
$$

Thus for a cathode to operate in spot mode with sufficient passive current collection,

$$
I_{D} \leq I_{A}
$$

Pottinger $^{33}$ conducted optical probe studies on the T6 hollow cathode at various positions along the emitter length. For a cathode operated at $5 \mathrm{~A}$ discharge current at $1.1 \mathrm{mg} / \mathrm{s}$ mass flow rate of argon, probes positioned at $2.7 \mathrm{~mm}$ upstream and $1.1 \mathrm{~mm}$ upstream of the cathode orifice determined electron temperature to be $\sim 0.6 \mathrm{eV}$ and $\sim 1.0 \mathrm{eV}$ respectively. Electron temperature did not vary significantly for discharge currents between $2 \mathrm{~A}$ to $10 \mathrm{~A}$. These measurements show good agreement with the spectroscopic measurements of Malik. ${ }^{34}$

The ionization fraction has been shown to approach unity with the orifice of hollow cathodes however, even if the T5 $\mathrm{HC}$ approaches full ionization at very high levels of orifice current density the propellant mass utilization through the 
keeper orifice does not, in general, exceed $10 \% .{ }^{35}{ }^{36}$ This latter parameter is defined as the ratio of extracted ion current over the equivalent current of $100 \%$ singly-ionized xenon. Such a discrepancy is likely caused by the fact that most ions of the ions created in the cathode orifice are neutralized before they can escape through the keeper orifice, ${ }^{35}$ even though it is located $\sim 2 \mathrm{~mm}$ downstream of the cathode. Inside the cathode, and even more so in the expanding plume, the electron temperature $T e$ is much lower than the first ionization potential for xenon $(12.13 \mathrm{eV})$. Recombination of ions and electrons within the emitted plasma is thus bound to be significant. ${ }^{37}$

Gessini clearly noted a transition to plume mode at flow rates below $0.5 \mathrm{mg} / \mathrm{s}$ with $5 \mathrm{Amps}$ discharge current on argon at which thrust noise, discharge noise and voltage were shown to sharply increase as shown in Figure 4.

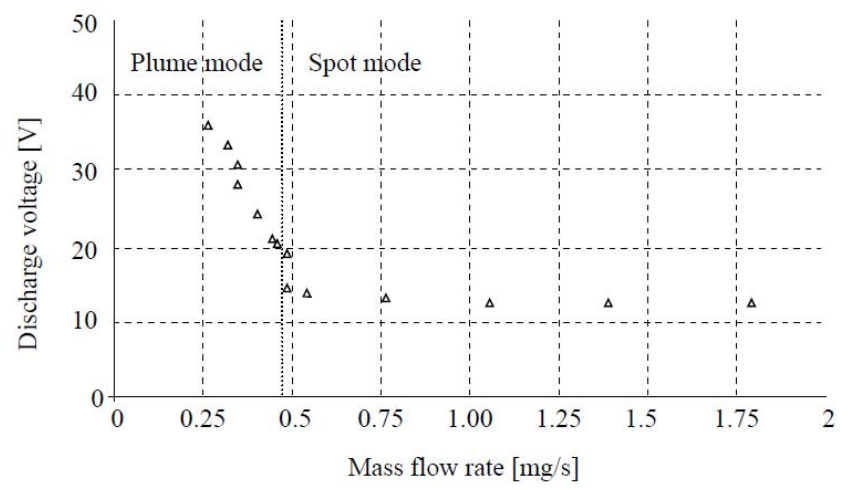

Figure 4 Transition from spot to plume mode at decreasing cathode flow rate with argon at $5 \mathrm{~A}^{38}$

Using the value of electron temperature of $1 \mathrm{eV}$ close to the orifice and the analytical model described previously along with the geometrical configuration of Gessini's anode, the required plasma density for plume mode transition at 5 Amps with $0.5 \mathrm{mg} / \mathrm{s}$ argon for the $\mathrm{T} 6$ cathode, as shown in Figure 4, can be evaluated. Gessini used a cylindrical anode of $10 \mathrm{~mm}$ diameter and $10 \mathrm{~mm}$ length. The ionization fraction required to satisfy the passive current condition of $5 \mathrm{~A}$ at the anode surface based on electron and ion temperature is shown in Figure 5. Since there are no direct measurements of ion temperature at this condition yet it strongly influences plasma density, the ionization fractions for ion temperatures of $0.1 \mathrm{eV}, 0.2 \mathrm{eV}, 0.4 \mathrm{eV}$ and $0.8 \mathrm{eV}$ are calculated, corresponding to heavy particle temperatures of $1160 \mathrm{~K}, 2321 \mathrm{~K}, 4642 \mathrm{~K}$ and $9284 \mathrm{~K}$ respectively.

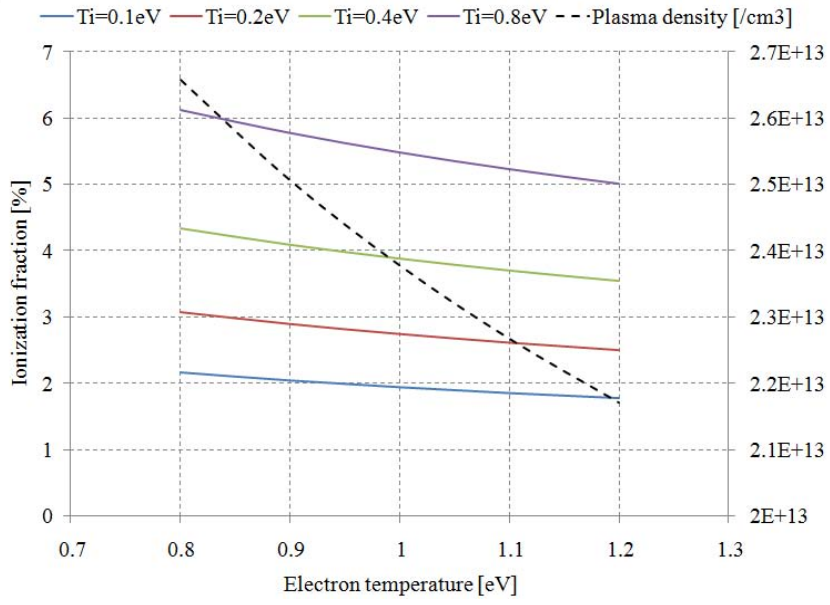

Figure 5 Calculated ionization fraction required to match empirical observations of Gessini for transition to plume mode at $5 \mathrm{~A}$ and $0.5 \mathrm{mg} / \mathrm{s}$ with a circular anode of $10 \mathrm{~mm}$ diameter and $10 \mathrm{~mm}$ length at respective electron and ion temperatures

Interestingly, increased ion temperature, while being important for the electrothermal thrust production mechanism, serves to lower the plasma density for a particular anode by increasing ion velocity and thus decreases $J_{e}$, thus the theoretical ionization fraction required to give spot mode increases. While ion temperature has a strong influence on the plasma density ion flux to the anode remains negligible in terms of constituting discharge current, as shown in Figure 6, given the low ion mobility. Electron temperature on the other hand does have a strong influence on the total discharge current and the current collection process.

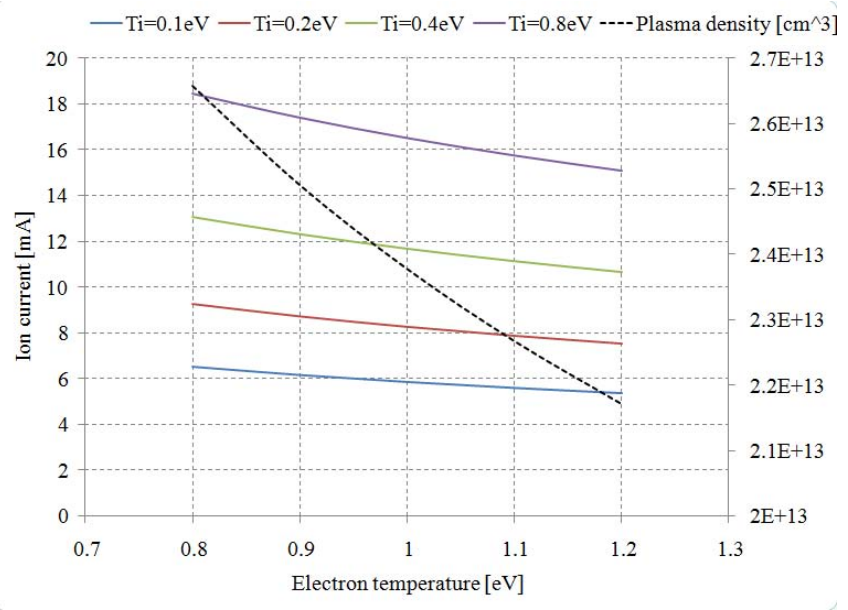

Figure 6 Passive ion current for changing ion and electron temperatures

The increase in ion current with decreasing electron temperature comes about by the increase in the required ionization fraction to give the 5Amps of passive discharge current. The ionization fraction bares the relation: 


$$
\alpha \propto \frac{I_{D}}{A_{A}}\left[\frac{T_{i}}{T_{e}}\right]^{0.5}
$$

Since $T_{i}, T_{e}$ and the attained ionization fraction $\alpha$ are largely functions of the cathode operating regime the most obvious way to increase the maximum passive current a cathode is capable of carrying is by increasing the available anode area to enhance electron collecting area. However, as suggested, plasma density significantly decreases downstream of the orifice (due to decreasing $\alpha$ ) and as such, so does the anodes capacity to passively collect current from the plasma. Measurements by Goebel ${ }^{40}$, shown in Figure 7, confirmed by the plasma models of Mikellides ${ }^{39}$ have shown that plasma density can decrease by nearly two orders of magnitude only $8 \mathrm{~mm}$ downstream of the orifice in the NSTAR discharge cathode. The NSTAR cathode in this case is a very useful comparison since the cathode orifice is of identical diameter to the T6 cathode used in our both our experiments and previous HCT experiments by Gessini on which our model is based.

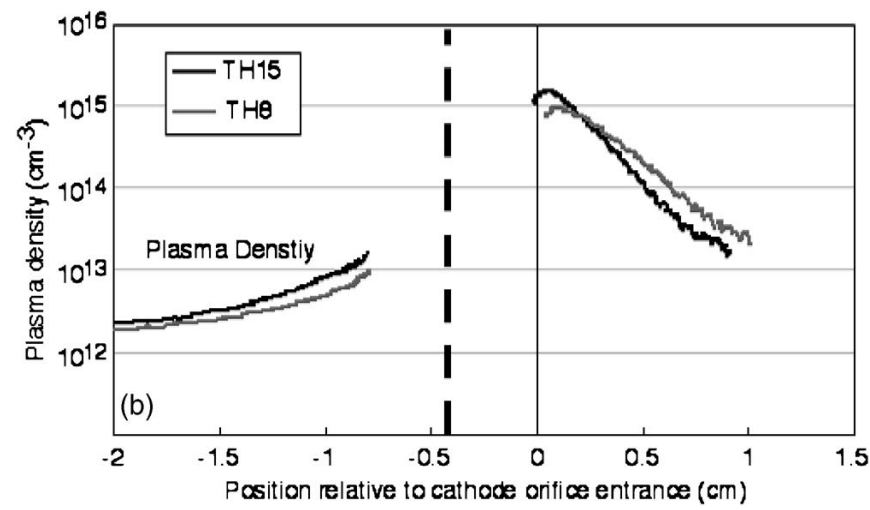

Figure 7 Plasma density falloff downstream of the cathode orifice in the $0.635 \mathrm{~cm}$ NSTAR discharge cathode with a $1 \mathrm{~mm}$ orifice. TH8 and TH15 correspond to discharge currents of $8.6 \mathrm{Amps}$ and $14.1 \mathrm{Amps}$ respectively ${ }^{40}$

The plasma densities calculated by our model for Gessini's anode match closely with the observed plasma densities found $10 \mathrm{~mm}$ downstream of the NSTAR cathode, in this case between $2.17-2.65 \times 10^{13} \mathrm{~cm}^{-3}$ for electron temperatures between $0.8-1.2 \mathrm{eV}$ respectively. This data confirms that, at least in this case, the analytical model is an accurate predictor of plume mode transition and strengthens the hypothesis that the plume mode transition occurs when $I_{D}>$ $I_{A}$. These data suggest that the most effective design of anode for maintenance of spot mode in HCTs may therefore be one which presents as greater area - plasma density product as possible. These two requirements are somewhat contradictory since, for instance, increasing the diameter of a cylindrical anode while increasing the available contact area also increases the path length for electrons and ions to traverse from the orifice, and as we have seen, ion recombination occurs quickly as the plasma exits the orifice, thus plasma density significantly drops. The problem of optimizing geometry may therefore be a complex one based on maximizing passive current collected for a range of operating conditions in which plasma density, ionization fraction, electron and ion temperature will vary as a complex function of the discharge current. Such optimization would require a significant modeling effort. Minimum anode geometry was thus calculated for a constant ionization fraction of $10 \%$ based on the measurements of Crofton for a maximum current of 25Amps. Mikellides presented a model of the geometrically similar NSTAR discharge cathode operating at $25 \mathrm{~A}$ on $5 \mathrm{sccm}$ of xenon $(0.35 \mathrm{mg} / \mathrm{s})$ and suggested a maximum heavy particle temperature of $2640 \mathrm{~K}$ or $0.227 \mathrm{eV}$ which we used as the ion temperature. Pottinger extensively characterized the internal plasma of the hollow cathode with xenon and recorded electron temperatures of $\sim 1.0 \mathrm{eV}$ at the orifice entrance at $25 \mathrm{~A}$ which we used as our electron temperature $T_{e}$. A conical anode with a $30^{\circ}$ divergent nozzle, as shown in Figure 8, was selected to as to satisfy the analytical model for the collection of a $25 \mathrm{Amp}$ passive current. The geometry of this particular anode became known as the T6 LA (large anode) and produced the highest specific impulse of all anode designs although various other anodes were built to explore discharge characteristics.

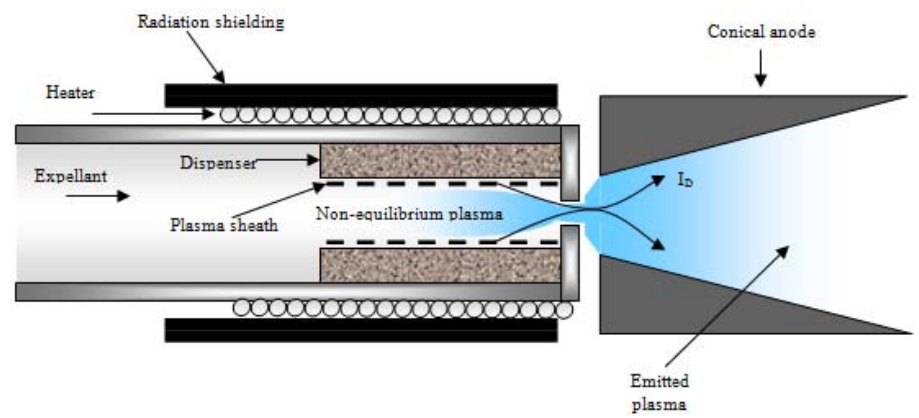

Figure 8 Schematic of the hollow cathode anode configuration

\section{Thermal Model of Anode Heating}

In anode design we must also consider heat dissipation and cooling of the anode. Since we want to avoid having to cool the anode actively here we will assume that the anode can only be cooled by conduction to the anode mountings and radiation to the vacuum. We have already described the power balance within the hollow cathode plasma.In this case the integrals of $J_{i}$ and $J_{e}$ are over the cathode and anode area in contact with the plasma. The energy absorbed by the anode from collection of the discharge current, ion recombination and radiative heat transfer from the plasma and cathode is given by: 


$$
\int J_{i}\left(\varepsilon_{i}+\frac{5 k T_{i}}{2 e}\right) d A_{A}+\int J_{e}\left(\frac{5 k T_{e}}{2 e}\right) d A_{A}+q_{r}+q_{c}
$$

In this case this energy will be rejected radiatively following the Stefan-Boltzmann law and conductively following Fourier's law, thus:

$$
\begin{aligned}
& \int J_{i}\left(\varepsilon_{i}+\frac{5 k T_{i}}{2 e}\right) d A_{A}+\int J_{e}\left(\frac{5 k T_{e}}{2 e}\right) d A_{A}+q_{r}+q_{c}= \\
& \int \varepsilon_{A}\left[T_{A}\right] \sigma T_{A}^{4} f_{A \rightarrow A} d A+C\left[T_{A}\right] \int \Delta T_{A} d A_{A}
\end{aligned}
$$

Where $f_{A \rightarrow A}$ is the view factor from the anode unit area to all other anode surfaces, $q_{r}$ is the radiative flux from the plasma to the anode and $\mathrm{q}_{c}$ is the radiative flux from the high temperature cathode body to the anode. This is in fact an over-simplification of the problem since there are many other important heat transfer routes not defined here such as the radiative and conductive transfer from the anode assembly to the cathode and supporting structure. Even so the evaluation of this problem to achieve a steady state solution is extremely mathematically challenging given the calculation of view factors, changes in thermal gradients, the fact that the analysis is an open radiation system with heat transfer to internal surfaces and as well as ambient vacuum. The evaluation of the $q_{c}$ component is also an extremely complex problem. In this case the thermal analysis tool COSMOS Flow Works was employed used for the calculation of steady state anode and assembly temperature. In order to evaluate the problem heat flux parameters had to be defined which from Equation 19 requires discharge current, electron temperature, ion current and ion temperature as well as the current distribution with respect to anode area. Since we are in this case building a thermal model and not a plasma model we assume that electrons are collected over the entire surface of the anode with constant $J_{e}$ for each anode. In reality this will vary with the plasma density and thus the anode will receive differential heat input however, since the anode will have a high degree of conductivity and will be relatively small in size, the peak anode temperature should not be substantially different from the mean anode temperature. Previous assumptions of electron temperature, ion temperature and ionization fraction for operation at $25 \mathrm{Amps}$ are used as in the previous analytical model. The output of the thermal model used to ensure the anode and assembly temperature was sufficiently cool is shown in Figure 9.

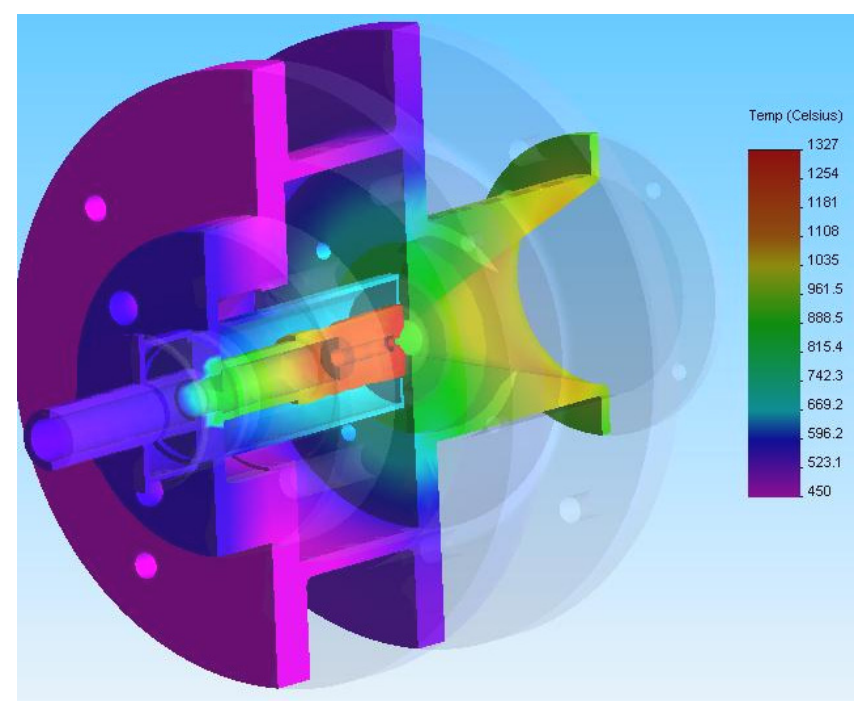

Figure 9 T6 Hollow cathode thruster assembly thermal model operating at $25 \mathrm{~A}$ with argon on $0.05 \mathrm{mgs}^{-1}$

\section{Thrust Measurement Data}

Various other geometrical configurations of thruster have been tested based on the configuration of the anode. Anode geometry was modified in order to establish the effect of plasma/anode contact area on the basis that this parameter has a strong influence on the transition of the cathode to plume type operation. Thrust characterization of the T5FO and the T6LA has been described by the author in previous papers $^{23,24,25}$ along with the laser optical lever thrust measurement system used. $^{41}$

\section{A. Thrust characteristics of the T5FO}

Figure 5 shows levels of specific impulse attained in a discharge mode. In a discharge mode results show near monotonic dependence of specific impulse on discharge current with rapidly increasing performance below $0.4 \mathrm{mgs}^{-1}$ for the $3.2 \mathrm{~A}$ and $1.6 \mathrm{~A}$ throttle settings with a less pronounced increase at $0.8 \mathrm{~A}$. Since a change in flow rate results in a change in operating voltage it specific impulse can be correlated with specific power of the flow (J.mg $\left.{ }^{-1}\right)$. Figure 10 shows the influence of mass flowrate on specific impulse with Figure 11 showing the relationship between specific power and specific impulse for the T5 cathode. 


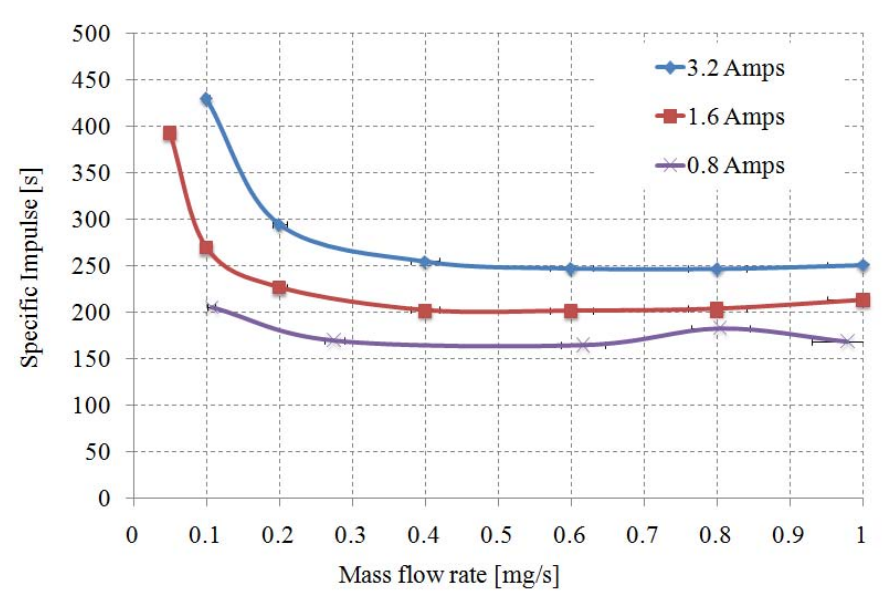

Figure 10 Specific impulse vs. mass flow rate for various throttle levels of the $T 5$ cathode

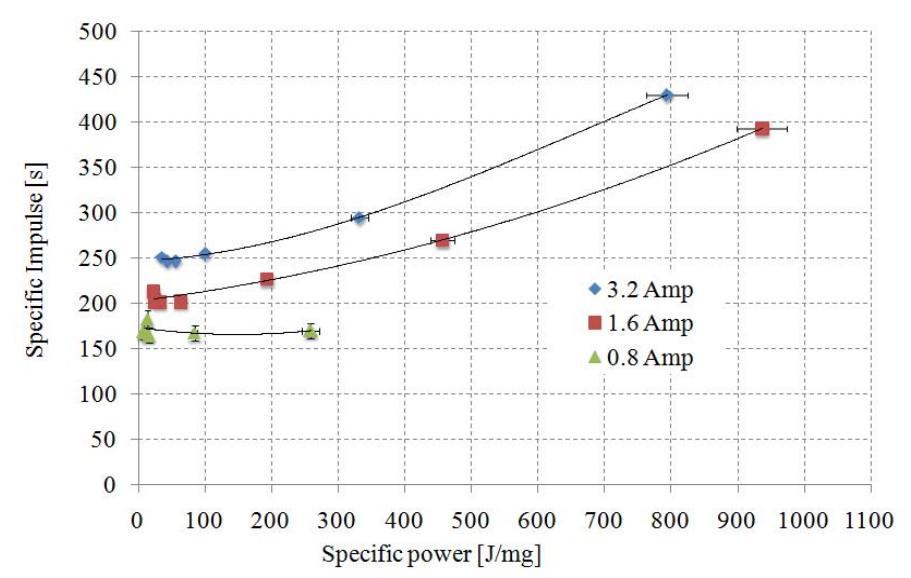

Figure 11 Dependence of specific impulse on specific power for the various current levels with argon

Operation at low powers $(<13 \mathrm{~W})$ in the low current condition (0.8Amp) brings relatively high specific impulse of up to 165 seconds equal to performance in a resistojet mode (and at lower power), where cathode body temperatures are in the region of $1000^{\circ} \mathrm{C}$. At the high current condition operation at powers of below $30 \mathrm{~W}$ give specific impulse in the region of 250s. Further reduction in flow rate increases operating voltage and power invested in the flow. This results in an increase in specific impulse however with declining thrust efficiency as convective and radiative losses begin to dominate.

\section{B. Thrust characteristics of the T6LA}

Figure 12 shows that in the T6LA achieving high specific impulse is dependent on discharge current since higher discharge currents are able to sustain operation at lower mass flow rates. Operation with xenon also gives high specific impulse although only at very low flowrates. This is testament to the lower primary ionization energy of xenon, which enabled the cathode to operate at the lowest flow rate of $0.04 \mathrm{mgs}^{-1}$.

Unlike the case of the T5 cathode, the T6 cathode shows relatively little improvement in specific impulse at higher currents indicating that resistive dissipation plays a much smaller role in thrust production, which is reasonable due to the large orifice of the T6 cathode. It is worth noting that at maximum current rated capacity, the current density in the T5 cathode is $65 \mathrm{~A} \cdot \mathrm{mm}^{-2}$ compared to the T6 cathode at 38A. $\mathrm{mm}^{-2}$ which, assuming an electrothermal acceleration mechanism, would suggest the reason for such larger relative changes in specific impulse of the $\mathrm{T} 5$ at higher currents.

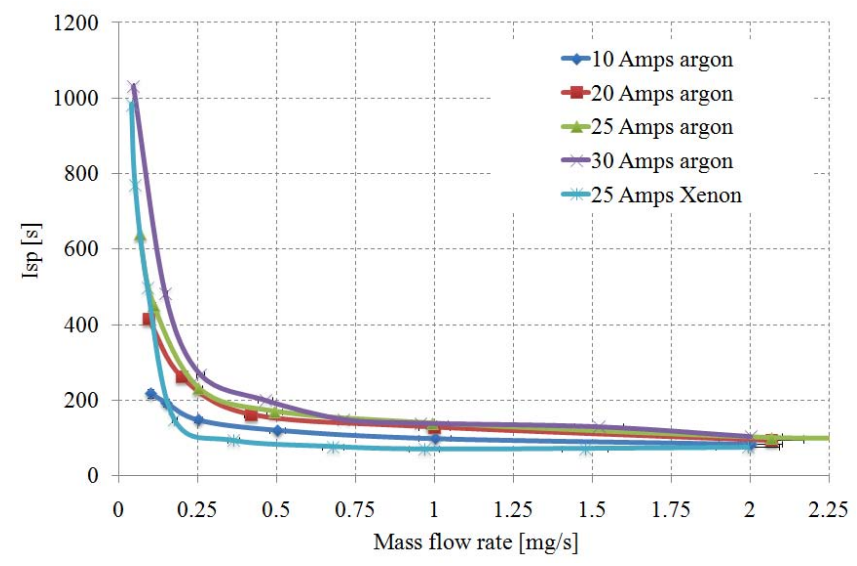

Figure 12 Specific impulse reached with the modified T6 hollow cathode at various current conditions and mass flow rates with xenon and argon

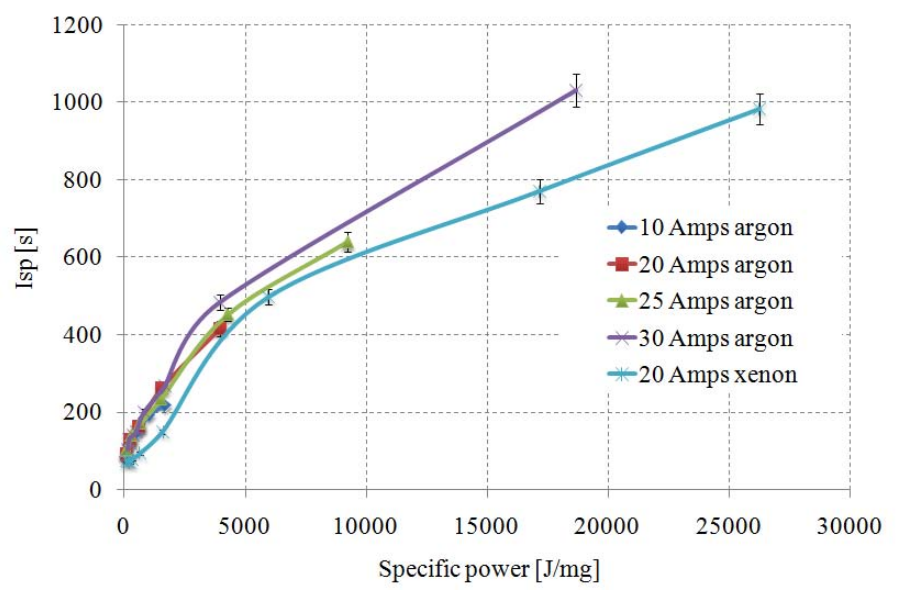

Figure 13 Relationship between specific impulse and specific power for the

\section{T6 at various current levels with xenon and argon}

Figure 13 shows two distinct gradients in the relationship between specific power and specific impulse which differ substantially from the T5 results. For operation with argon, specific impulse is almost identical for low specific powers, however approaching 5000J.mg ${ }^{-1}$ there is a change in 
gradient. It is postulated that this change in gradient is also a change in dominant thrust mechanism, with electromagnetic acceleration becoming the dominant since flow rates above $5000 \mathrm{~J} . \mathrm{mg}^{-1}$ are very low and would contribute an increasingly small degree of electrothermal thrust. This hypothesis is strengthened when considering thrust level with respect to mass flow rate as in Figure 14.

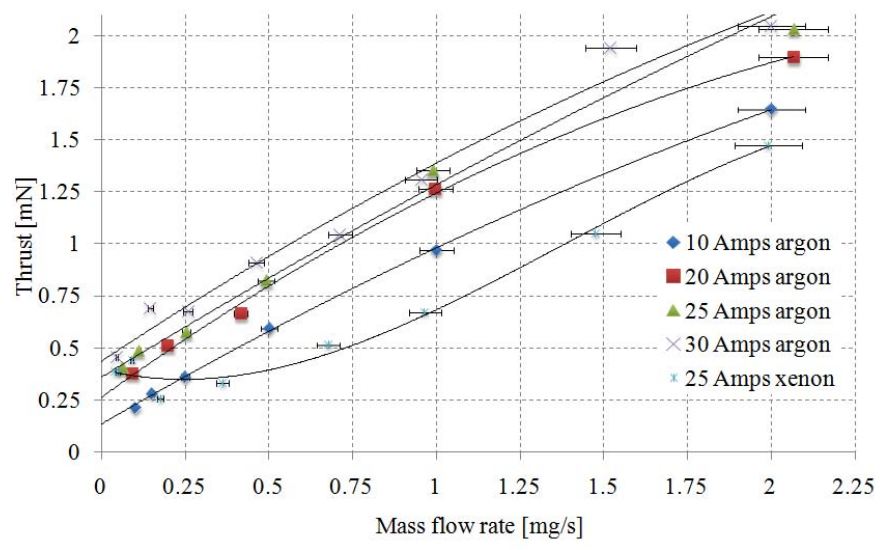

Figure 14 T6 thrust level with respect to mass flow rate at various current conditions with xenon and argon

It is clear that when extrapolating thrust level back to zero mass flow a remnant thrust production mechanism exists which scales with discharge current. The thrust measurement with the heavier xenon propellant however has different characteristics to operation with argon. Above $0.25 \mathrm{mgs}^{-1}$ thrust scales almost linearly with mass flowrate however at below $0.25 \mathrm{mgs}^{-1}$ the thrust measurement moves the intercept close to that of argon at the same current level.

\section{Anode Geometry Investigations}

In an attempt to both understand thrust production and to improve efficiency, anode geometry was modified, as previously mentioned, to enable operation at lower flowrates and also reduce discharge voltage to improve efficiency. Anode geometry was shown to have a significant influence on both the point of transition to plume mode and also the discharge voltage when operating at a specific discharge current and mass flow rate. The operating voltages of the T5 cathode with argon for both forms of anode are shown in Figure 15. With the larger anode and at low mass flowrates the discharge voltage is shown to be 8$10 \mathrm{~V}$ below that of an orificed flat plate anode. In this case, due to mass flow meter limitations, the larger anode was only operated below $0.4 \mathrm{mg} / \mathrm{s}$. Nonetheless, at the $3.2 \mathrm{Amp}$ current condition the conical anode reduces discharge voltage from $34.57 \mathrm{~V}$ for the flat plate to $19.35 \mathrm{~V}$, a reduction of $15.22 \mathrm{~V}$. This increases discharge efficiency by $44 \%$ and also substantially influences noise generation.

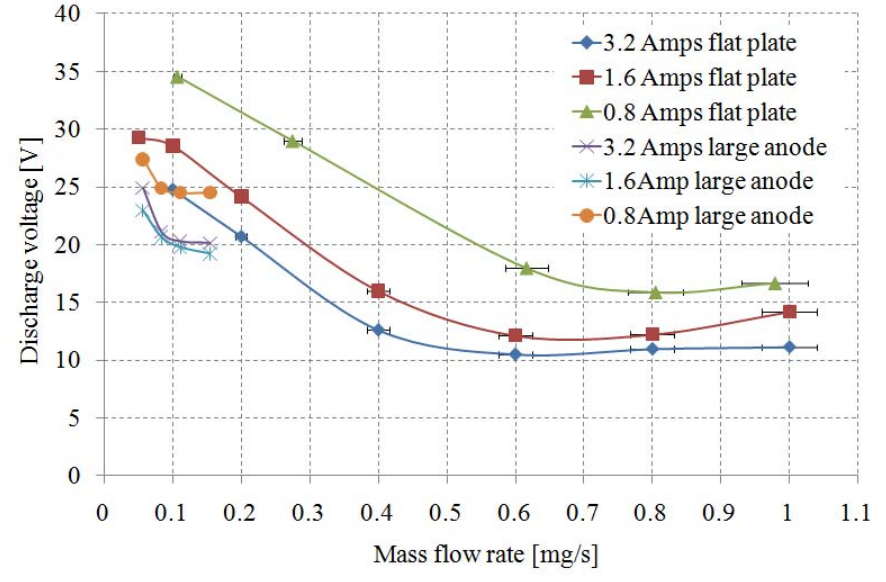

Figure 15 T5 voltage characteristics when operating in a T5FP and T5CA configuration on argon

With a flat plate anode the cathode gradually enters plume mode as flow rate is reduced below $0.25 \mathrm{mg} / \mathrm{s}$ however using a CA type configuration maintains spot mode like operation to much lower flowrates, only entering plume mode at the reduction of flow rate to extreme levels close to the extinguishing flowrate. Figure 16 shows the T5CA operating in an almost noise free DC discharge when operating on only $0.05 \mathrm{mg} / \mathrm{s}$ of argon. Further reduction to $0.03 \mathrm{mg} / \mathrm{s}$ however results in substantial noise generation primarily $<5 \mathrm{MHz}$ but also extending beyond $120 \mathrm{MHz}$ as shown in Figure 17.

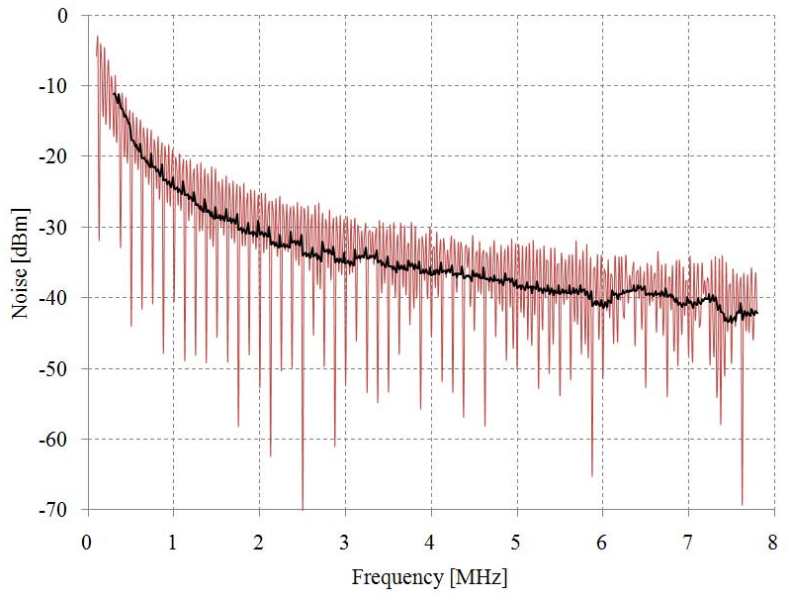

Figure 16 Noise measurements from a T5CA operating on $0.05 \mathrm{mg} / \mathrm{s}$ argon at $3.2 \mathrm{Amps}$ 


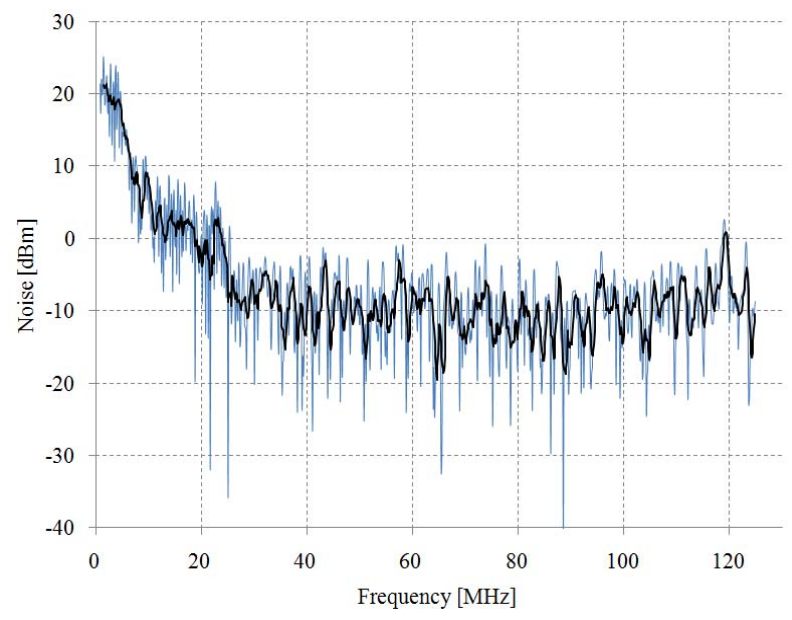

Figure 17 Noise measurements from a T5CA operating on $0.03 \mathrm{mg} / \mathrm{s}$ argon at $3.2 \mathrm{Amps}$

Similar behavior, shown in Figure 18, is found in operation of the T6VLA cathode however transition in this case occurs at an order of magnitude higher flowrates than the T5CA cathode.

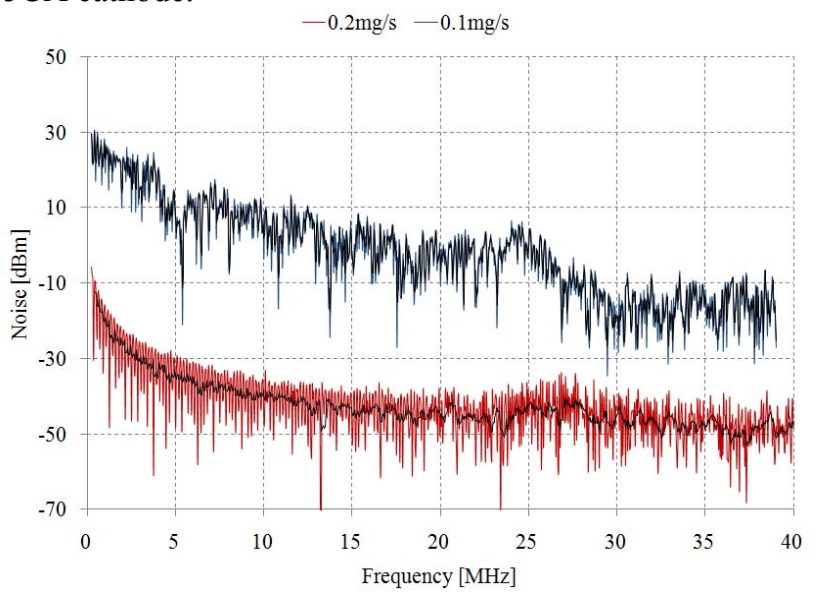

Figure 18 Noise measurements from the T6VLA operating at $0.2 \mathrm{mg} / \mathrm{s}$ and $0.1 \mathrm{mg} / \mathrm{s}$ on argon at $25 \mathrm{Amps}$

With both the T5 and T6 cathodes, transition to plume mode transition occurs at increasingly higher flowrates with decreasing discharge currents. Anode type also has a pronounced effect on this transition point with respect to mass flowrate however at the time of writing this data is still being collected. Voltage data highlighting the abruptness of the change to plume mode is shown in Figure 19. This data was taken at 5 Amps with a change in flowrate from $1.5 \mathrm{mg} / \mathrm{s}$ to $1.45 \mathrm{mg} / \mathrm{s}$ and back again. The cathode initially shows very little noise, however on decreasing mass flowrate the cathode very quickly establishes a transition to a slightly higher operating voltage $(1-2 \mathrm{~V}$ unstable) but with significant noise generation and peak to peak voltages in excess of $9 \mathrm{~V}$.

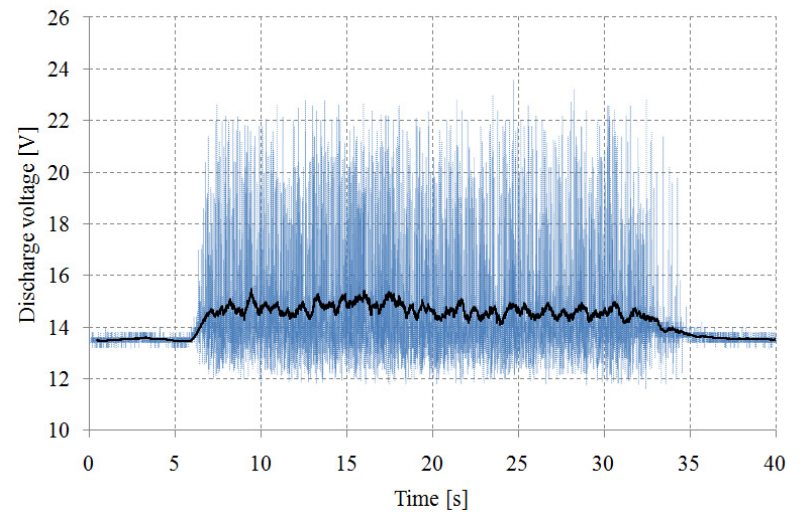

Figure 19 Voltage characteristics of a transition to plume mode at 5Amps on argon between $1.5 \mathrm{mg} / \mathrm{s}$ $1.45 \mathrm{mg} / \mathrm{s}$ and back again.

\section{Anode Heat Flux}

Due to the convective heat flux of electrons, particularly in the case of the T6 cathode which operates at much higher currents, anode temperatures can be in excess of $2500 \mathrm{~K}$. The ability of the anode to radiatively dissipate heat flux determines the maximum current any particular anode configuration is able to operate at. In addition smaller anodes result in larger operating voltages which also results in increased heat flux since electrons are of higher energy due to the additional voltage drop which results in an increase in electron temperature. Voltage characteristics of the T6SA and T6VLA shown in Figure 20. The maximum current for the T6SA was $17.5 \mathrm{~A}$ at higher flowrates and $12.5 \mathrm{~A}$ at lower flowrates as opposed to the T6MA, T6LA and T6VLA which were able to

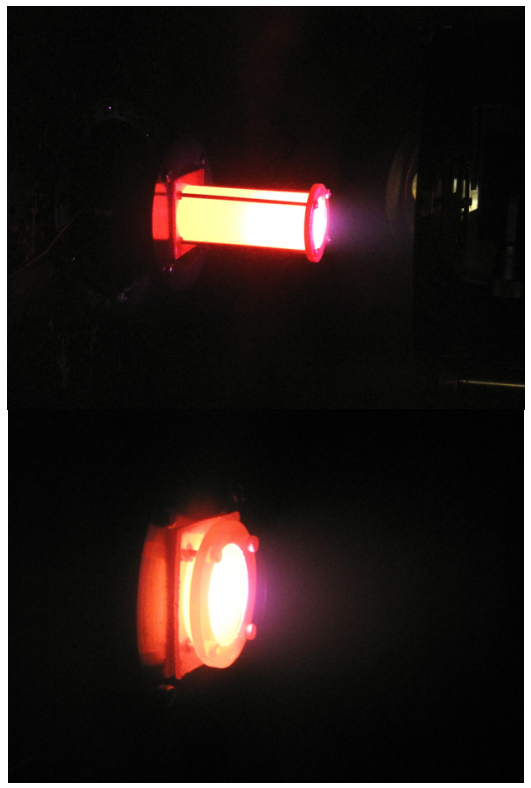

Figure 20 T6VLA operating at 25A, 0.1mg/s (top) T6 SA operating at $12.5 \mathrm{~A}, 0.1 \mathrm{mg} / \mathrm{s}$ (bottom) 


\section{DISCUSSION}

\section{A. Thrust Mechanisms}

Plasma models suggest that cathodes are capable of generating peak heavy particle temperatures greater than $6,000 \mathrm{~K}$ with wall temperature not exceeding $1,500 \mathrm{~K}{ }^{42}$ Laser Induced Fluorescence (LIF) has identified neutral temperatures in cathode-keeper gaps are between 1800$4000 \mathrm{~K}$, well above cathode wall temperature. ${ }^{43}$ Experiment has also suggested heavy particle temperatures between $3200-6000 \mathrm{~K}$ necessary to explain elevated backpressures within conventional cathodes. ${ }^{44}$ Assuming the plasma and remaining neutrals undergo some degree of adiabatic expansion it is reasonable to assume some level of thermal energy conversion to directed kinetic energy of the flow which is dependent on the plasma heating modes. The main mechanism of plasma heating is known to be Ohmic heating by plasma electrons within the cathode orifice with collisional heat transfer to the heavy particles. ${ }^{45}$ A thermal thrust mechanism with significant arc heating within the cathode would be possible while low wall temperatures are maintained $(<1700 \mathrm{~K})$ given the low plasma densities contacting the orifice $\left(\sim 10^{20} / \mathrm{m}^{3}\right)^{46}$ The electron temperature within the orifice is typically $11,600-23,200 \mathrm{~K}(1-2 \mathrm{eV})$, depending on the degree of Ohmic heating. The performance of any electrothermal device can be approximated by means of a rudimentary one-dimensional energy argument that limits the exhaust speed of the flow from a fully expanded nozzle to:

$$
v_{e x} \leq \sqrt{C_{p} T_{p r o p}}
$$

When considering thermalization of the propellant to produce thrust with xenon, krypton or argon, the theoretical limit to specific impulse (assuming full conversion of thermal to directed kinetic energy) is shown in Figure 21.

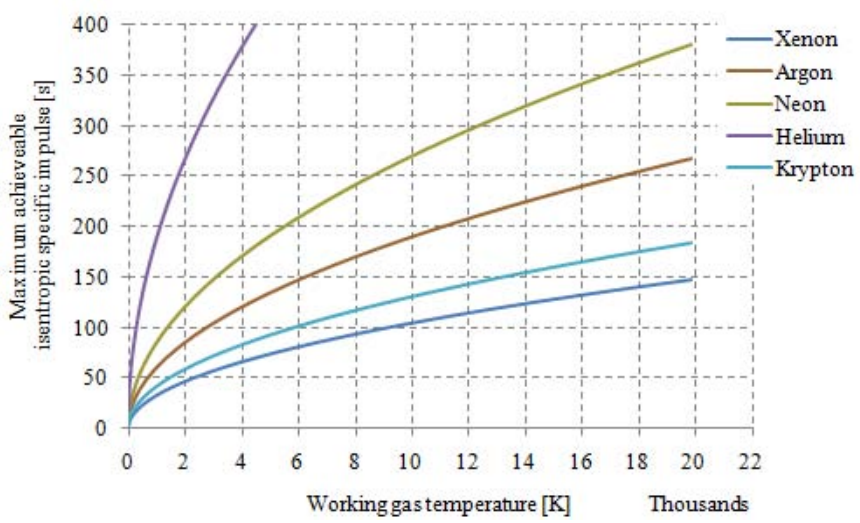

Figure 21 Limiting specific impulse for purely thermalized propellants based on full energy conversion

An electrothermal thrust mechanism is sufficient to explain specific impulse $<250$ s found in the T5 cathode at flowrates above $0.2 \mathrm{mg} / \mathrm{s}$ which would require propellant temperatures $<6000 \mathrm{~K}$. However at flowrates below this it is not easy to conceive of heavy particle temperatures $>16,000 \mathrm{~K}$ required for specific impulse up to $450 \mathrm{~s}$. As flowrate is reduced further it is however conceivable that the ionisation fraction increases considerably, thus so does plasma density. It is also conceivable that electron temperature increases significantly with reduced mass flowrate as the cathode is forced to operate at higher voltages in order to sustain operation. In this case there is an increasingly significant additional component of pressure thrust at the orifice exit. Assuming the propellant leaves the cathode at the chocked flow velocity and no form of nozzle is included downstream of the orifice, the thrust contribution at the orifice exit will thus consist of components of momentum and pressure thrust at the orifice exit given by:

$$
\begin{aligned}
& F=\dot{m}\left[\alpha \sqrt{\gamma R_{x e} T_{i}}+(1-\alpha) \sqrt{\gamma R_{x e} T_{n}}\right] \\
& +A_{\mathrm{o} r}\left(n_{e} k T_{e}+n_{i} k T_{i}+n_{n} k T_{n}\right)
\end{aligned}
$$

In this case is can be seen that this additional component of thrust when considering moderate electron temperatures and ionization fractions can account for the high values of specific impulse found when operating the T5FO cathode. In addition, transient thrust measurements made as the cathode is switched off, shown in Figure 22, indicates a significant backpressure component is removed within the cathode. As the cathode is switched off there is a significant increase in thrust, between $40-50 \%$ of the discharge thrust level, which gradually decreases to a level consistent with the hot gas thrust. As the mass flow is then switched off the thrust level reduces to zero. The rate of decrease in thrust at both points in time is equal indicating that the reduction in thrust immediately after the thrust increase at switch-off is also due to expulsion of an upstream pressure buildup within the cathode and feed lines.

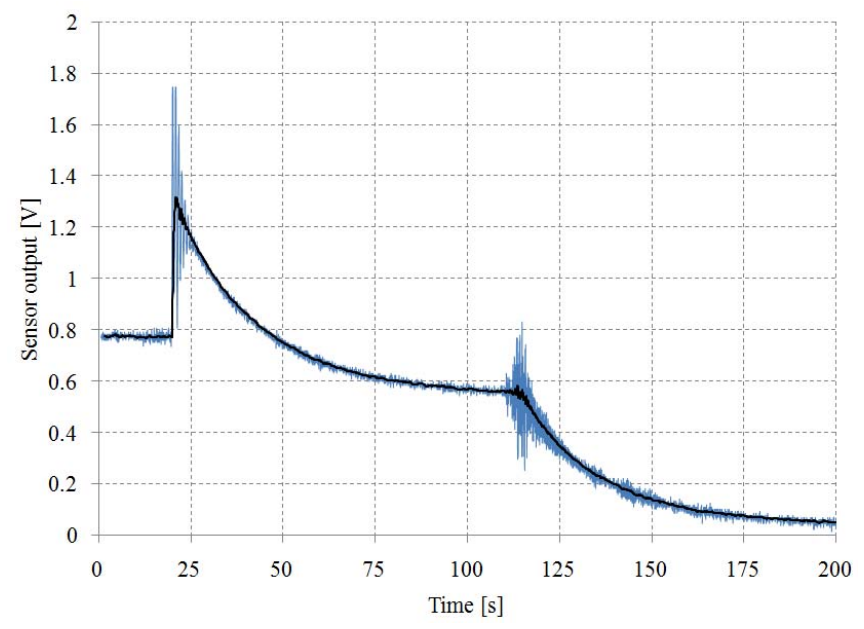

Figure 22 Thrust measurement as the cathode discharge 
is switched off at $t=23 \mathrm{~s}$ with constant upstream mass flowrate followed by the mass flow being turned off at $t=115 \mathrm{~s}$. The cathode is operating at $3.2 \mathrm{~A}$ with $2 \mathrm{mg} / \mathrm{s}$ xenon

As a first approximation, assuming that all particles behave like a perfect dilute gas, the plasma pressure in the hollow cathode orifice can be evaluated from the equation of state:

$$
p_{\mathrm{o} r}=n_{e} k T_{e}+n_{i} k T_{i}+n_{n} k T_{n}
$$

Considering the small orifice area compared to the cross sectional area of the internal diameter of the cathode, the internal pressure may, as a first approximation, be estimated from the critical flow relation for sonic flow through the orifice, assumed to be adiabatic.

$$
p_{\text {ins }}=p_{o r}\left(1+\frac{\gamma-1}{2}\right)^{-1 /(\gamma-1)}
$$

In this case it can be seen that a reduction in orifice plasma pressure backpressure would cause an increase in mass flow due to an increased pressure difference. Since the mass flow into the feed lines and cathode is constant this pressure difference would eventually reduce to the critical pressure ratio for a choked orifice as the upstream pressure diminishes which can be clearly seen in Figure 22.

\section{E. T6 Hollow Cathode Thruster with Large Anode (T6LA) Thrust Mechanism}

Accounting for the specific impulse found from the T6LA also requires heavy particle temperatures too high to be described by a thermal thrust mechanism alone. Unlike the T5FO, the T6LA may experience a degree of electromagnetic acceleration of the charged particles by Lorenz forces in the plasma, which is reasonable above 25 Amps. The T5FO cathode however operates at much lower currents and therefore is expected to operate in an almost purely electrothermal mode.

A T6 cathode with of $0.75 \mathrm{~mm}$ orifice diameter orifice at $30 \mathrm{Amps}$ would give a current density of $6.8 \times 10^{7} \mathrm{~A} / \mathrm{m}^{2}$. Assuming that the plasma does not pinch, the magnetic field at the edge of the orifice is would be considerable at 160 Gauss and higher if the plasma is assumed to pinch. If a strong self-induced magnetic field exists within the orifice it may be sensible to suggest the possibility of magnetohydro-dynamic acceleration of the plasma.

The Maecker formula has been used to approximate the thrust scaling of self-field magneto-plasma-dynamic thrusters (MPDTs) with the total current. The formula has been shown to be too simplistic to account for the trends in measured thrust data at low current due to the scaling of gas dynamic pressure distributions induced by the pinching components of the volumetric electromagnetic forces. ${ }^{47}$ However in this case it can be used as an approximation of the significance of the EM force alone.

A stream wise acceleration could be provided by the crossing of the radial arc current $J$ with the self generated azimuthal magnetic field through the cathode orifice, an essentially scalar crossed-field interaction with an anode and cathode radius $r a$ and $r c$ given by:

$$
F_{z}=\frac{\mu J^{2}}{4 \pi}\left(\ln \frac{r_{A}}{r_{c}}+\frac{3}{4}\right)
$$

The resulting particle velocity assuming a fully ionized gas is shown in Figure 23.

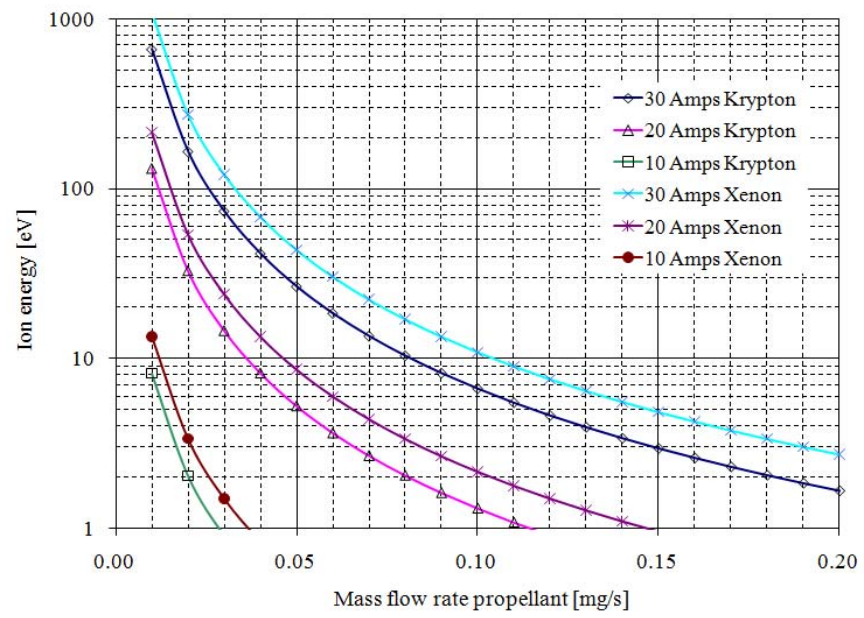

Figure 23 Theoretical ion energies from the Maecker formula as a result of the cross field interaction from a self-generated azimuthal magnetic field for krypton and xenon acting on a fully ionized mass flow

Assuming a bulk accelerating force acts on the total mass flowrate it can be seen that the resulting accelerating force per particle is significant. One important factor considered in MPDT's type operation is the exceeding of the critical ionization current. Assuming MPDT theory can serve as a first approximation, it can be shown that if flow rates are low enough the ratios of discharge current $I$ to the critical ionization current, $I_{c i}$ also becomes significant. A key scaling parameter of interest is, $\xi$, the ratio of the discharge current to (also known as the full ionization current). ${ }^{48} 4950$ Parameters such as the thrust and voltage have been seen to strongly correlate with $\xi$ in MPDTs. The plasma is considered partially ionized at $I<I_{c i}$ and fully ionized for $I>I_{c i}$. At $\mathrm{I}=\mathrm{I}_{\mathrm{ci}}(\xi=1)$, the electromagnetic thrust is equal to the product of the mass flow rate and the propellant Alfven critical ionization velocity. The parameter $\xi$ is given by Eqn.(17), and Jci is given by Eqn.(18) where: 


$$
\begin{gathered}
\xi=\left(\frac{I^{2}}{\dot{m}} \frac{\mu_{0} \ln \left(r_{A} / r_{c}\right)}{4 \pi\left(2 \varepsilon_{i} / M\right)}\right)^{1 / 2}=\frac{I_{i}}{I_{c i}} \\
I_{c i}=\left(\frac{\left(\dot{m} 2 \varepsilon_{i} / M\right)^{1 / 2}}{\frac{\mu_{0}}{4 \pi} \ln \left(r_{A} / r_{c}\right)}\right)^{1 / 2}
\end{gathered}
$$

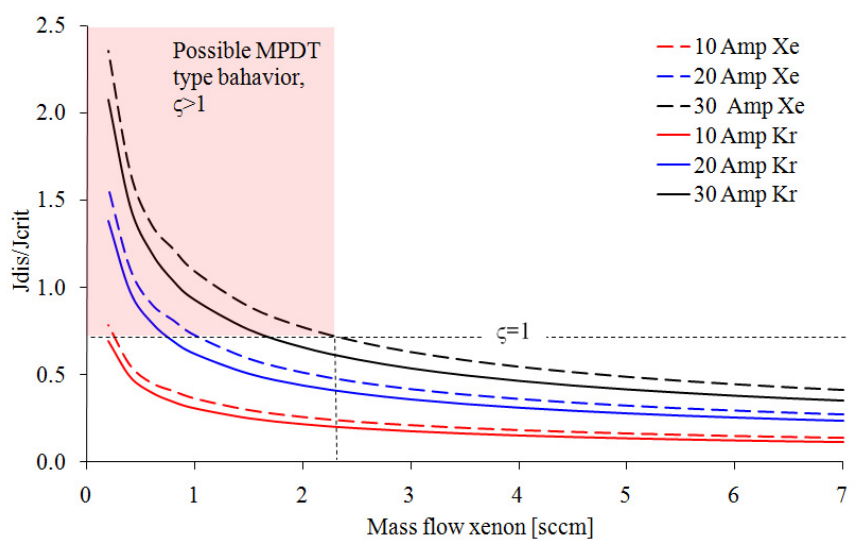

Figure 24 Ratio of critical ionization current to discharge current with xenon and krypton for a cathode anode geometry similar to that used in this experiment

In Figure 24 it can be seen that for operation with xenon and krypton (argon would lay between the two) operation at low flow rates $<1 \mathrm{sccm}$ at currents above $30 \mathrm{Amps} \xi=1$. Below $\xi=1$ the flow is only partially ionized while at $\xi>1$ the flow can be expected to be highly ionized and may exhibit behavior similar to MPDT's.

If the thrust production mechanism in the $\mathrm{T} 6$ hollow cathodes was indeed more electromagnetic at low flowrates rather than electrothermal the electromagnetic component of thrust level should be independent of cathode and orifice operating pressures and appear almost instantaneously as the discharge is switched on and off. This data can be seen in the transient thrust measurement in Figure 25.

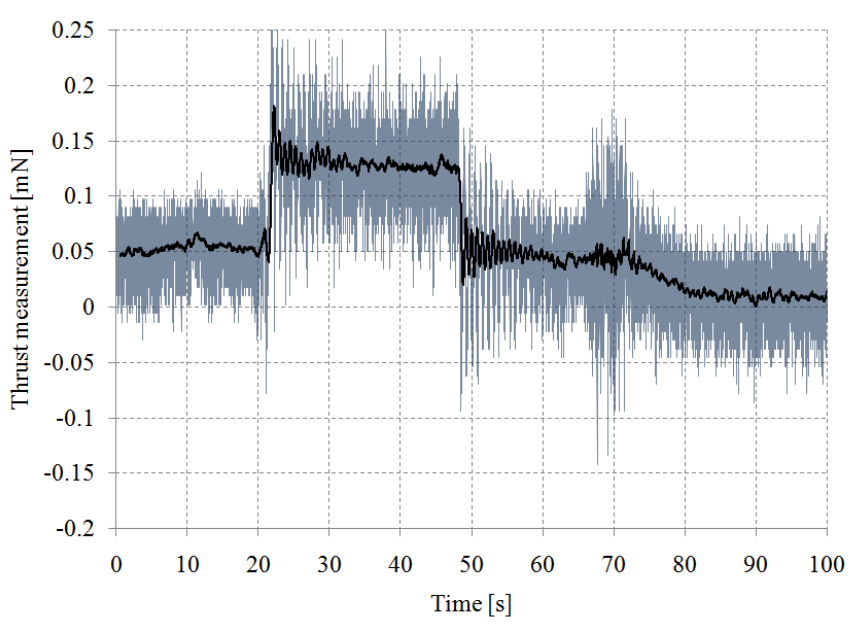

Figure 25 Transient thrust measurement as T6LA is switched on at $t=22$, off at $t-47$ and the mass flow is switched off at $t=70$. Cathode is operated at $25 \mathrm{Amps}$ with $0.2 \mathrm{mg} / \mathrm{s}$ argon

As seen above the additional thrust component appears almost instantaneously (with some delay due to the inertia of the target thrust balance) as the discharge is switched on and removed instantaneously as the discharge is extinguished. As the mass flow is switched off however a characteristic transient is seen as the cathode and feed lines depressurize. If the thrust component which appears during the discharge was indeed electrothermal it would take 10-20 seconds to reach steady state as seen in the mass flow switch-off transient however it does not. In addition the theoretical MHD thrust determined by the Maecker formula for a similar geometrical configuration to the T6 cathode matches close to the thrust extrapolations level at zero mass flowrate as shown in Figure 26.

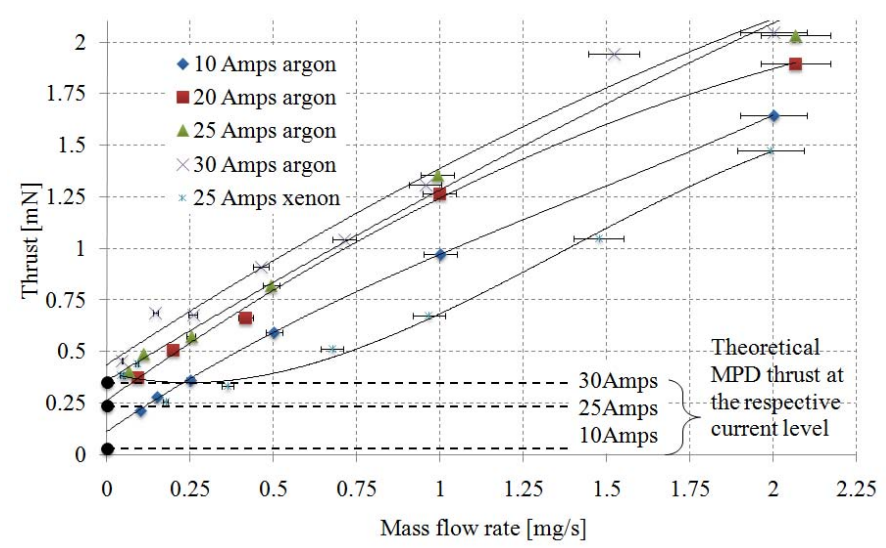

Figure 26 T6 thrust characteristics with theoretical MHD thrust at the respective current levels

This data strengthens the hypothesis that the T6LA operates in an MPDT type mode at low flowrates and high currents. 


\section{F. Electrostatic acceleration}

One other mechanism which could also play a role in the thrust generation in both the T5CA and T6LA is electrostatic acceleration of ions through a potential drop due to the formation of a region of positive plasma potential. The existence of this positive column has been seen extensively in experimental measurements and has been proposed as a means of acceleration as ions fall down the potential hill. The structure of the plasma potential is of particular interest because it may also be directly associated with the attainable ion energies. High energy ion erosion has been identified as the most probable near-term cause of failure during extended life tests at NASA JPL on the NSTAR ion thruster. ${ }^{51}$. The plasma density and potential profiles downstream of the keeper electrode in the NSTAR hollow cathode have been extensively measured with scanning probes by Herman and Gallimore ${ }^{52}$, Jameson, et al. ${ }^{53}$, and by Sengupta, et al. ${ }^{54}$.

The source of the energy to produce these ions in excess of $90 \mathrm{eV}$ is likely to be RF plasma potential oscillations in the near cathode plume from plasma instabilities. ${ }^{55}$ Goebel postulated that the source of these plasma potential oscillations is likely turbulent ion acoustic waves generated in the hollow cathode discharge plasma or ionization instabilities termed predator-prey modes in the near-cathode plume region. Evidence indicates that discharge plasma potential oscillations measured by Goebel et al. had amplitudes about twice the average discharge voltage, large enough to account for high energy ions accelerated through the potential gap between the oscillation peak and cathode potential. $^{56}$

Although ions of extreme energies have been attributed to these RF plasma oscillations, the existence of a spatially rising plasma potential cannot be ignored as a source of bulk ion acceleration. It has been sufficient to regard the spatial or temporal profiles of the plasma potential obtained by the measurements were sufficient to be considered the mechanism for the generation and direction of high-energy ions well in excess of the discharge voltage. The details of how discharges establishes a spatially rising plasma potential downstream of the keeper or the reasons for the absence of a non-monotonic profile have not yet been fully identified and explained.

In the case of a potential hill, an electric field exists across a plasma potential drop:

$$
E=-d V / d x
$$

In this case, the velocity gained by a singly charged particle moving through the potential is:

$$
V_{e}=\left[\frac{2 e\left(V_{0}-V_{f}\right)}{M}\right]^{1 / 2}
$$

The ion velocity at any point follows from conservation of energy to give the particle velocities shown in Figure 27.

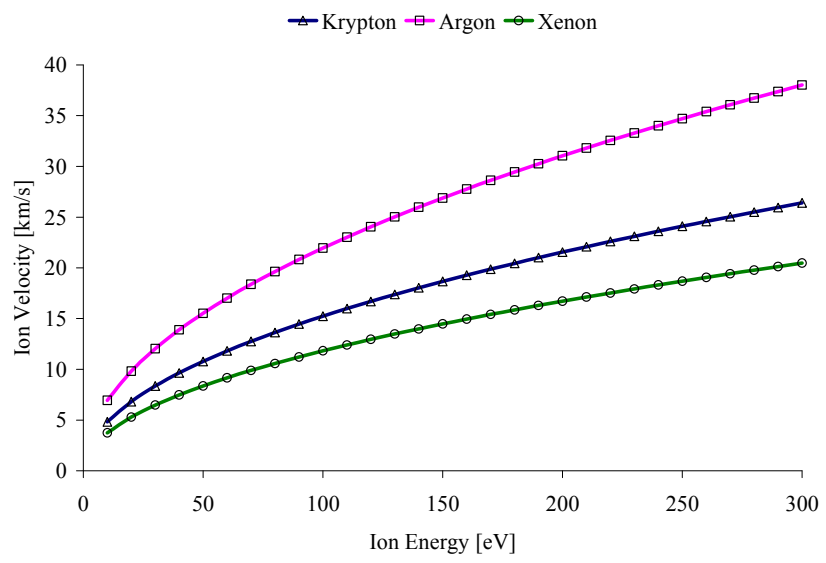

Figure 27 Corresponding ion velocities with krypton and xenon for a given energy

Investigations by the author ${ }^{57}$ on a $1 / 4$ inch hollow cathode with an electrostatic energy analyzer operating on xenon and krypton have shown that bulk acceleration of ions is found, particularly with increasing discharge current and decreasing mass flowrate, where peak plasma potentials are likely to increase. An example of this bulk acceleration is shown in Figures 28 and 29 for xenon.

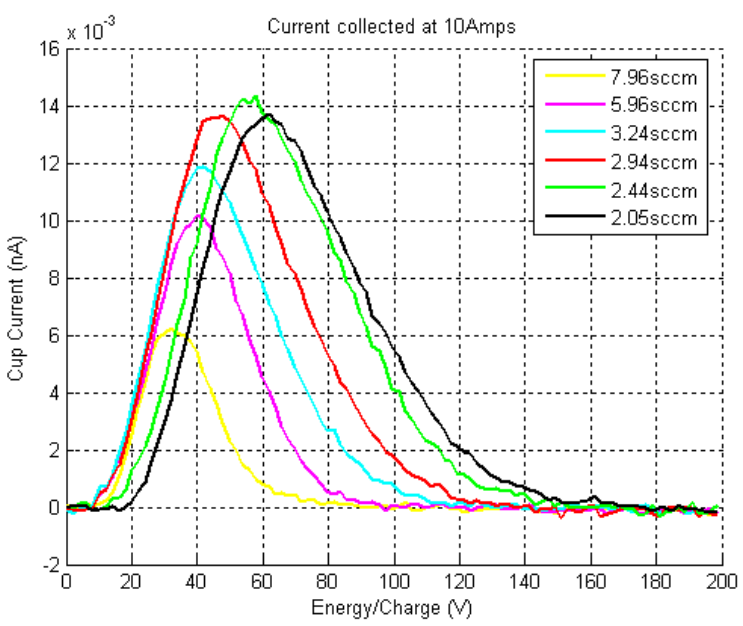

Figure 28 Ion energy distributions at 10 amps with xenon

At 10Amps discharge current the ESA data shows slightly energy peaks up to $62.4 \mathrm{eV}$ which are likely caused by ion acoustic waves. However the plot also begins to show a bulk acceleration of the $2.44 \mathrm{sccm}$ and $2.05 \mathrm{sccm}$ conditions 
$(<20 \mathrm{eV})$ whereby the complete distribution is shifted up in energy; a process exemplified at higher currents. At 16Amps Figure 26 shows peak ion energies are significantly higher than for the 10Amp condition and with much greater bulk acceleration of plasma; the data for the $2.05 \mathrm{sccm}$ flow condition for instance shows little to no ions with energies less than $35 \mathrm{eV}$. The $2.94 \mathrm{sccm}$ condition shows a decrease in collected current contrary to the trend which may be due to some thermal movement, MHD vectoring of the plume or plume expansion.

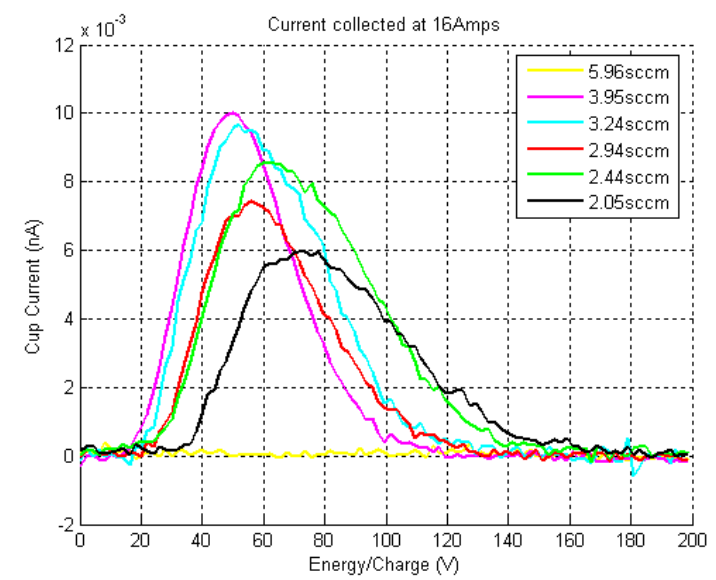

Figure 29 Ion energy distributions at 16 amps with xenon

Since no measurements of plasma potential have been made of the T5 or T6 configurations it is not possible to confirm or deny the significance of such a mechanism in our thrust measurements however such a mechanism would only be significant if the plasma was highly ionized and remained in that state through the acceleration process. If this were the case then plasma potential hill acceleration may play a role in thrust production. Future investigations will aim to identify the role of this mechanism in thrust production by taking plasma potential measurements.

\section{CONCLUSION}

An overview of the design considerations for hollow cathode thruster optimization has been presented along with data collected from configurations of the T5 and T6 hollow cathode thrusters. The basis for several thrust production mechanisms has been proposed.

Analysis of the T5CA results indicate that the thrust mechanism may be explicable by electrothermal type operation in a conventional gas-dynamic mode however with significant plasma pressure contributing to increased thrust as a result of the electron pressure component at the orifice exit. The exact thrust mechanisms of the T6 hollow cathode have been debated for some time. Our results indicate that for high specific impulse there is considerable evidence that at high currents and low flowrates, the hollow cathode operates as a low power MPD thruster. Due to the relatively low currents, electron convective and radiative losses dominate performance and thus give poor thrust efficiencies. If this is the case, operation at elevated currents is likely to significantly improve performance and thrust efficiency; although this will be well beyond the rated current capacity for the T6 cathode. Indeed multi-channel hollow cathodes have been proposed and built for MPD thrusters for some time. If the hollow cathode thruster is to have a place in the family of MPD accelerators, it may be as a very low power thruster $<2 \mathrm{~kW}$ (owing to the low discharge voltages) with very little power conditioning required. Thrust efficiencies are unlikely to improve significantly since this will scale quadratically with discharge current and will quickly enter much higher power regimes of operation. Analysis would indicate that while electrothermal acceleration does play a role in $\mathrm{T} 6$ thrust production, it does not increase significantly as mass flow is decreased. This suggests that either electron temperature does not increase significantly at lower flow rates or that the energy equipartition between electrons-ions and electronneutrals remains too low for any substantial increase in heat transfer. If the flow in the T6 cathode is also substantially ionized it has also been shown that plasma potential hill acceleration may play a role in thrust production however this requires further investigation.

Further detailed analysis is required to verify the existence of each mechanism and to understand the best means in which to utilize them to give greater performance. Further work is also required on anode design in order to optimize performance and increase efficiency. The low voltages obtained in the T6LA and T5CA designs highlight the importance of plasma anode interaction and anode geometry. Previously keeper design has been considered relatively insignificant; however as has been shown optimized keeper design is imperative for hollow cathode thrusters, but also for neutralizers for Hall thrusters, ion engines and plasma contactors for minimization of discharge voltage.

\section{REFERENCES}

${ }^{1}$ Gray, H L, "Development of ion propulsion systems", GEC Rev, 12, 3, 154-168, 1997.

${ }^{2}$ Wallace, N C and Feam, D G, "The design and performance of the T6 ion thruster", AIAA Paper 98-3342, 1998.

${ }^{3}$ Fearn, D, Singfield, A, Wallace, N, Gab-, S and Harris, P, "The operation of ion thruster hollow cathodes using rare gas propellants", AIAA Paper 90-2584, 1990.

${ }^{4}$ Latham, P M, Martin, A R and Bond, A, "Design, manufacture and performance of the UK-25 engineering model thruster", AIAA Paper 90-2541, 1990.

${ }^{5}$ Harris, P T and Gair, S, "A review of the cathode construction for the RAE 10/25 mN thruster", IEPC Paper 88-078, 1988.

6 Philip, C M and Fearn, D G, "Recent hollow cathode investigations at the Royal Aircraft Establishment", AIAA paper 73-1137, (1973); AIAA J, 12, 10, 1319-25, 1974.

${ }^{7}$ Fearn, D G, "The operation of hollow cathodes under conditions suitable for ion beam neutralization", Proc Conf on Electric 
Propulsion of Space Vehicles, Culham Laboratory, UK, (April 1973). Inst of Electrical Engineers Conference Publication 100, pp 146-150, 1973.

${ }^{8}$ S. Pottinger, P. Gessini, D. Webb, R. Intini Marques and S. B. Gabriel, "Electric Propulsion Research at the University of Southampton", Journal of the British Interplanetary Society, Vol. 59, No. 5, May 2006.

9 P. Gessini, S. B. Gabriel and D. G. Fearn, "Thrust Characterization of a T6 Hollow Cathode", IEPC Paper 05-257, $29^{\text {th }}$ International Electric Propulsion Conference, Princeton, NJ, October-November 2005.

${ }^{10}$ P. Gessini, S. B. Gabriel and D. G. Fearn, "The T6 Hollow Cathode as a Microthruster", AIAA Paper 2005-4078, 41 ${ }^{\text {st }}$ AIAA/ASME/SAE/ASEE Joint Propulsion Conference \& Exhibit, Tucson, AZ, July 2005.

${ }^{11}$ QinetiQ Study, European Student Moon Orbiter

${ }^{12}$ Walker, R., "The SIMONE Mission: low-cost Exploration of the Diverse NEO Population via Rendezvous with Microsatellites", IAC-03-Q.5.05 54th International Astronautical Congress of the International Astronautical Federation, the International Academy of Astronautics, and the International Institute of Space Law, Bremen, , Sep. 29-3, 2003

${ }^{13}$ Rayman, Marc D. and David H. Lehman, "NASA's First New Millennium Deep-Space Technology Validation Flight," Second IAA International Conference on Low-Cost Planetary Missions, Laurel, MD, April 16-19, 1996, IAAL-0502.

${ }^{14}$ P. Bodin, S. Berge, M. Bjork, A. Edfors, J. Kugelberg and P. Rathsman "The SMART-1 Attitude and Orbit Control System: Flight Results from the First Mission Phase", AIAA-2004-5244 AIAA Guidance, Navigation, and Control Conference and Exhibit, Providence, Rhode Island, Aug. 16-19, 2004

15 H. Kuninaka, Y. Shimizu, T. Yamada, I. Funaki and K. Nishiyama,"'Flight Report During Two Years on HAYABUSA Explorer Propelled by Microwave Discharge Ion Engines", AIAA-2005-3673, 41st AIAA/ASME/SAE/ASEE Joint Propulsion Conference and Exhibit, Tucson, Arizona, July 10-13, 2005

${ }^{16}$ Rayman, M. D., Fraschettia, T. C., Raymonda, C. A., Russell C. T, "Preparing for the Dawn Mission so Vesta and Ceres", IAC-05A3.5.B.011, 56th International Astronautical Congress, 17 - 21 October 2005, Fukuoka, Japan,

17 Moerel, J., Marée, T., Bombelli, V., Simon D., "Economic Benefits of the Use of Non-Toxic Mono-Propellants for Spacecraft Applications" , AIAA-2003-4783 39th AIAA/ASME/SAE/ASEE Joint Propulsion Conference and Exhibit, Huntsville, Alabama, July 20-23, 2003

${ }^{18}$ Richie E. Wirz.. Dissertation: Discharge Plasma Processes of Ring-Cusp Ion Thrusters, Ph.D. Thesis, California Institute of Technology 2005

19 Gesini, P., "Hollow Cathode Thrust Measurement Using a Target”, PhD Thesis, University of Southampton, 2006

${ }^{20}$ Jankovsky, R. S., Sankovic, J. M., Oleson, S., "Performance of a FAKEL K10K resistojet", AIAA-1997-3059 AIAA/ASME/SAE/ASEE Joint Propulsion Conference and Exhibit, 33rd, Seattle, WA, July 6-9, 1997

${ }^{21}$ Coxhill, I., Gibbon, D.,"A Xenon Resistojet Propulsion System for Microsatellites", $\quad$ AIAA-2005-4260 41st AIAA/ASME/SAE/ASEE Joint Propulsion Conference and Exhibit, Tucson, Arizona, July 10-13, 2005

${ }_{22}$ Grubisic A.N., Gabriel S.B., "Development of an Indirect Measurement Micro-to-Milli-Newton Thrust Balance" American Institute of Astronautics and Aeronautics, Journal of Propulsion and Power, (pending) pp.15
${ }^{23}$ Grubisic A.N., Gabriel S.B., "Thrust Characterization of the TSeries Hollow Cathode Microthrusters" American Institute of Astronautics and Aeronautics, Journal of Propulsion and Power, (pending): pp.32

${ }^{24}$ Grubisic A.N., Gabriel S.B., "Hollow Cathode Thrusters for AllElectric Spacecraft" IAC-07-C4.4.07, 58 ${ }^{\text {th }}$ International Astronautical Federation Congress, Hyderabad, India, September 2007

${ }^{25}$ Grubisic A.N., Gabriel S.B. D. G. Fearn, "Characterization of the T-Series Hollow Cathode Thrusters for All-Electric Spacecraft" IEPC-2007-81, 30 ${ }^{\text {th }}$ International Electric Propulsion Conference, Florence, Italy, September, 2007

${ }^{26}$ Grubisic A.N., "Ion Energies in an Open-Diode Hollow Cathode Discharge" AIAA-2008-5095, Joint Propulsion Conference, Connecticut Convention Centre, Hartford, CT, July, 2008

27 Polk J.E., Grubisic A. N., Goebel D., "Emitter Temperature Distributions in the NSTAR Discharge Hollow Cathode" AIAA2005-4398, $41^{\text {st }}$ AIAA/ASME/SAE/ASEE Joint Propulsion Conference, Tucson, AZ, 2005

28 Grubisic A.N., "Temperature Characterization and Optimization of an NSTAR Discharge Cathode for the Deep Space-1 Gridded Ion-Engine" Masters Thesis, International Space University, Strasbourg, France 2005

${ }^{29}$ Sarver-Verhey, T. R., "28,000 Hour Xenon Hollow Cathode Life Test Results,” IEPC Paper No. 97-168 (1997).

${ }^{30}$ Rawlin, V. K., “A 13,000 Hour Test of a Mercury Hollow Cathode," NASA TM X-2785 (1973).

${ }^{31}$ Rehn, L. and Kaufman, H.R., "Correlation of Inert Gas Hollow Cathode Performance," AIAA Paper No. 78-707 (1978).

32 Mandell, M.J. and Katz I., "Theory of Hollow Cathode Operation in Spot and Plume Modes," AIAA. Paper No. 94-3134, 30th AIAA/ASME/SAE/ASEE Joint Propulsion Conference

${ }^{33}$ Pottinger S J and Gabriel S B 2003 IEPC 28th Int. Electric Propulsion Conf. (Toulouse, France, 17-21 March 2003

34 Malik, AK, Montarde, P, Haines, MG, Spectroscopic measurements on xenon plasma in a hollow cathode, J PHYS D APPL PHYS, 2000, Vol: 33, Pages: 2037 - 2048

${ }^{35}$ Mark W. Crofton, "The Feasibility of Hollow Cathode Ion Thrusters: A Preliminary Characterization," AIAA-2000-5354, $36^{\text {th }}$ AIAA/ASME/SAE/ASEE Joint Propulsion Conference and Exhibit, July 16-19, 2000.

${ }^{37}$ A. K. Malik, D. G. Fearn, "The Study of the Physics of Hollow Cathode Discharges," IEPC-93-026, AIAA/AIDAA/DGLR/JSASS 23rd International Electric Propulsion Conference, September 1316, 1993.

38 P. Gessini, S. B. Gabriel and D. G. Fearn, "Thrust Characterization of a T6 Hollow Cathode", IEPC Paper 05-257, $29^{\text {th }}$ International Electric Propulsion Conference, Princeton, NJ, October-November 2005

${ }^{39}$ G. Mikellides , I. Katz, D.M. Goebel, J.E. Polk, "Theroretical Model of a Hollow Cathode Plasma for the Assesment of Insert and Keeper Lifetimes", 41st AIAA Joint Propulsion Conference, Arizona, 2005

${ }^{40}$ Goebel, D. M., Jameson, K. K., Katz, I, and Mikellides 1. G., "Potential fluctuations and energetic ion production in hollow cathode discharges", Phys. Plasmas, Vo1.14, 2007, 103508.

41 Grubisic A.N., Gabriel S.B., "Development of an Indirect Measurement Micro-to-Milli-Newton Thrust Balance" American Institute of Astronautics and Aeronautics, Journal of Propulsion and Power, (pending) pp. 15

${ }^{42}$ Sahli, A., Turchi, P.J., "Low Power Plasma Thruster Based on a 
Hollow Cathode Discharge”, AIAA Paper No. 94-3126 (1994).

43 Williams, G., Smith, T., Domonkos, M., Shand, K., and Gallimore, A., "Laser Induced Fluorescence Characterization of Ions Emitted from a Hollow Cathode," AIAA Paper No. 99-2862 (1999).

${ }^{44}$ Domonkos, M. T., Gallimore, A. D., and Patterson, M. J., "An Evaluation of Hollow Cathode Scaling to Very Low-power and Flow Rate," IEPC Paper No. 97-189 (1997).

${ }^{45}$ Katz, I. and Patterson, M. J., "Optimizing Plasma Contactors for Electrodynamic Tether Missions," Tether Technology Interchange, Huntsville, AL, Sept. 1997.

46 Mikellides I., Katz ., Goebel D. M., and Polk J. E., , "Theoretical Model of a Hollow Cathode Plasma for the Assessment of Insert and Keeper Lifetimes", AIAA Paper No. 2005-4234 (2005).

47 Choueiri, E., "On the Thrust of Self-Field MPD Thrusters" IEPC-97-121, International Electric Propulsion Conference, 1997

48 Choueiri, E. Y., "Scaling of Thrust in Self-Field Magnetoplasmadynamic Thrusters," Journal of Propulsion and Power, Vol. 14, No. 5, 1998, pp. 744-753.

${ }^{49}$ Diamant, K. D., Choueiri, E. Y., and Jahn, R. G., "Spot mode transition and the anode fall of pulsed magnetoplasmadynamic thrusters," Journal of Propulsion and Power, Vol. 14, No. 6, 1998, pp. 1036-1042.

${ }^{50} 1$ Choueiri, E. Y., Kelly, A. J., and Jahn, R. G., "MPD thruster instabilities studies," 19th International Electric Propulsion Conference, Colorado Springs, CO, 1987, AIAA-87-1067.

51 Sengputa, A. "Destructive Physical Analysis of Hollow Cathodes from the Deep Space 1 Flight Spare Ion Engine 30,000Hr Life Test". 29th International Electric Propulsion Conference, IEPC-2005-026, 2005

52 19D. Herman and A. Gallimore, "Near discharge cathode assembly plasma potential measurements in a 30-cm NSTAR type ion Engine", AIAA Paper 2004-3958, 40th Joint Propulsion Conference, Ft. Lauderdale, FL, July 11-14, 2004.

${ }^{53}$ 15K. Jameson, D.M. Goebel, R. Watkins, "Hollow cathode and keeper region plasma measurements", AIAA Paper 2005- 3667, 41th Joint Propulsion Conference, Tucson, AZ July 11-13, 2005.

${ }^{54} 20$ A. Sengupta, "Experimental investigation of discharge plasma magnetic field confinement in an NSTAR thruster", AIAA Paper 2005-4069, 41th Joint Propulsion Conference, Tucson, AZ July 11-13, 2005.

${ }^{55}$ D.M. Goebel, D.M. Goebel, K. Jameson, I. Katz, I. Mikellides, J. Polk, "Energetic Ion Production and Keeper Erosion in Hollow Cathode Discharges" IEPC-2005-266, 29th International Electric Propulsion Conference, Princeton University, Oct. 31- Nov. 4, 2005.

${ }^{56}$ D.M. Goebel, D.M. Goebel, K. Jameson, I. Katz, I. Mikellides, J. Polk, "Energetic Ion Production and Keeper Erosion in Hollow Cathode Discharges" IEPC-2005-266, 29th International Electric Propulsion Conference, Princeton University, Oct. 31- Nov. 4, 2005

${ }^{57}$ Grubisic A.N., "Ion Energies in an Open-Diode Hollow Cathode Discharge" AIAA-2008-5095, Joint Propulsion Conference, Connecticut Convention Centre, Hartford, CT, July, 2008

\section{BIOGRAPHY}

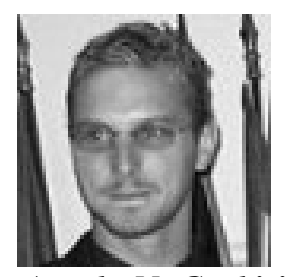

Angelo N. Grubisic was born on the $24^{\text {th }}$ of June 1981. He received his Bachelor of Engineering degree in Aerospace Systems Engineering from Coventry University in 2003 followed by a Master of Science in Space Studies from the International Space University in 2005. In 2006 he spent a year as a propulsion researcher based with Surrey Satellite Technology Ltd. and Surrey Space Centre. In 2009 he was awarded a PhD in Advanced Propulsion from the University of Southampton. In 2008 Dr. Grubisic was placed with NASA Jet Propulsion Advanced Propulsion Group as part of an entrepreneurial Kauffman Fellowship. Currently Dr. Grubisic is a Research Fellow at the University of Southampton. His research interests include hollow cathode, electron guns, gridded ion thrusters and spacecraft systems engineering.

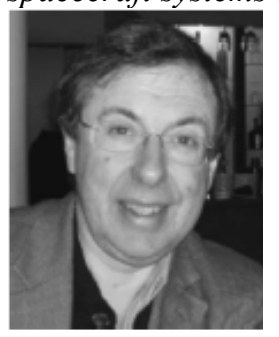

Stephen B. Gabriel was born on August 13, 1949 in Glasgow, U.K. He received the B.Sc. degree in natural philosophy and the Ph.D. degree in plasma physics from the University of Strathclyde, Glasgow, in 1971 and 1977, respectively. From 1975 to 1979, he was a Postdoctoral Research Fellow with the Department of Aeronautical Engineering, Bristol University, Bristol, U.K. From 1979 to 1983, he was a Member of the Staff with the Electric Propulsion and Plasma Technology Group at the Jet Propulsion Laboratory (JPL), California Institute of Technology, Pasadena, where he mainly worked on electric propulsion, including gridded ion thrusters and MPDs, and plasma spacecraft interactions. From 1983 to 1985, he was a Senior Systems Engineer with the British Aerospace, Space and Communications Division, Stevenage, U.K., where he led small systems engineering propulsion teams on several ESA studies. In 1985, he returned to the JPL to become Group Supervisor with the Natural Space Environments Group within the Reliability Engineering Section, where he worked on many of the major interplanetary missions, such as Magellan, Galileo, and Cassini, as well as other missions such as Topex. In 1990, he returned to the U.K. to become a Lecturer with the Department of Aeronautics and Astronautics, University of Southampton, Southampton, 
where he was promoted as a Senior Lecturer in 1995 and a Personal Chair, Professor of Aeronautics and Astronautics, in 2003. His current main research interests include the fields of electric propulsion, including hollow cathodes, advanced gridded ion thrusters and pulsed plasma thrusters, space environments, in particular, solar energetic particle modeling and X-ray and UV effects on materials, and formation flying of nanosatellites. 